\title{
Article \\ Comparison of Biological Efficiency Assessment Methods and Their Application to Full-Scale Biogas Plants
}

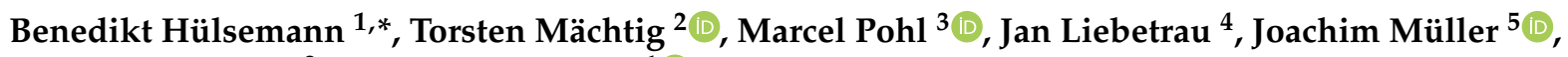 \\ Eberhard Hartung ${ }^{2}$ and Hans Oechsner ${ }^{1}$ (D) \\ 1 State Institute of Agricultural Engineering and Bioenergy, University of Hohenheim, Garbenstraße 9, \\ 70599 Stuttgart, Germany; hans.oechsner@uni-hohenheim.de \\ 2 Institute of Agricultural Engineering, Kiel University, Olshausenstraße 40, 24098 Kiel, Germany; \\ tmaechtig@ilv.uni-kiel.de (T.M.); ehartung@ilv.uni-kiel.de (E.H.) \\ 3 DBFZ Deutsches Biomasseforschungszentrum Gemeinnützige GmbH, Biochemical Conversion Department, \\ Torgauer Straße 116, 04347 Leipzig, Germany; Marcel.Pohl@dbfz.de \\ 4 Rytec $\mathrm{GmbH}$, Consulting and Research, Pariser Ring 37, 76532 Baden-Baden, Germany; \\ jan.liebetrau@rytec.com \\ 5 Tropics and Subtropics Group, Institute of Agricultural Engineering, University of Hohenheim, \\ 70599 Stuttgart, Germany; joachim.mueller@uni-hohenheim.de \\ * Correspondence: Benedikt.Huelsemann@uni-hohenheim.de; Tel.: +49-711-459-23371
}

Citation: Hülsemann, B.; Mächtig, T.;

Pohl, M.; Liebetrau, J.; Müller, J.;

Hartung, E.; Oechsner, H.

Comparison of Biological Efficiency

Assessment Methods and Their

Application to Full-Scale Biogas

Plants. Energies 2021, 14, 2381.

https://doi.org/10.3390/en14092381

Academic Editor: Attilio Converti

Received: 19 March 2021

Accepted: 20 April 2021

Published: 22 April 2021

Publisher's Note: MDPI stays neutral with regard to jurisdictional claims in published maps and institutional affiliations.

Copyright: (c) 2021 by the authors. Licensee MDPI, Basel, Switzerland. This article is an open access article distributed under the terms and conditions of the Creative Commons Attribution (CC BY) license (https:// creativecommons.org/licenses/by/ $4.0 /)$.

\begin{abstract}
For calculation of biological efficiency of a biogas plant (BP), it is required to determine the specific methane potential (SMP) of the substrate. A study comparing available methods for determination of SMP and the comparison with data of full-scale BPs is missing but necessary according to the differences in process conditions between both. Firstly, mass and mass associated energy balances of 33 full-scale BPs were calculated and evaluated. The results show plausible data for only $55 \%$ of the investigated BPs. Furthermore, conversion and yield efficiencies were calculated according to six different methods for SMP determination. The results show a correlation between the measured on-site specific methane yield and the calculated SMP by methods based on biological degradability. However, these methods underestimate the SMP. Calculated SMPs based on calorific values are higher, but less sensitive. A combination of biochemical and energetical methods is a promising approach to evaluate the efficiency.
\end{abstract}

Keywords: anaerobic digestion; biochemical methane potential test; fermentable organic dry matter content; gross calorific value; mass and energy balance

\section{Introduction}

In Germany alone, approximately 8700 biogas plants (BP) were in operation in the year 2020 with an installed capacity of $6.2 \mathrm{GW}_{\mathrm{el}}$ in total [1]. However, the installation of new BPs has come to a near standstill in recent years, mainly due to the lower feed-in tariffs and premiums for electricity generation from the amendments to the Renewable Energy Sources Act (EEG) since 2012 [2]. At the same time, BPs built before 2012 will phase out from their guaranteed 20-year time period of tariffs and premiums in the coming years [3]. In order to compensate for falling tariffs, the substrate conversion rate has to be increased. Therefore, methods are needed to assess the biological process efficiency. The efficiency of a conversion process like anaerobic digestion can be defined by the extent of conversion of an initially available potential of the substrate in two ways: (i) the, produced methane related to the methane potential of the substrate called yield efficiency (YE) in the following and (ii) the actually used potential, i.e., the differences between the methane potential of the substrate and the residual methane potential of the digestate related to the methane potential of the substrate, called conversion efficiency (CE) in the following.

While the substrate is weighed and recorded in most full-scale biogas plants, the output in the form of digestate and biogas is hardly ever measured and must therefore be 
estimated. Schievano et al. [4] estimated the methane production of the full-scale biogas plant based on the electricity generation of the combined head and power plant (CHP). Thus, under steady state conditions the mass of digestate can be calculated from the mass balance of the input (substrate) and output (biogas and digestate).

In addition to the mass flows, the methane potential of substrates and digestates must be estimated. Various approaches to this problem can be found in the literature. Several studies are based on organic dry matter content (ODM) degradation ( $\left.\mathrm{CE}_{\mathrm{ODM}}\right)$ [5-7]. Since the range of substrates typically used in practice varies greatly in terms of the proportion of anaerobically degradable organic matter, a substrate-independent comparison of BPs with this method is not possible [8]. To overcome this disadvantage, other methods based on a more precise determination of the anaerobic conversion potential of substrates have been developed. One of the most common methods is the so-called biochemical methane potential test (BMP), which is a laboratory batch test performed according to VDI 4630 [9]. Anaerobic biodegradability and microbial growth are considered by the method and the methane potential can be calculated directly for any kind of substrates and digestates. Several impact factors were reported and show which efforts are necessary for getting reproducible results $[10,11]$. To create a common database for specific methane yields of commonly used substrates, BMP results of various laboratories were compiled and published by the Association for Technology and Structures in Agriculture (KTBL) [12], which are referred to as "KTBL values" in the following.

However, the KTBL values do not consider the effects of natural fluctuation in dry matter content (DM), ODM and the degradability of ODM. These parameters are considered by a method based on fermentable organic dry matter (FOM), which was developed by Weißbach [13]. The FOM represents a part of ODM, from which the non-degradable organic fraction is subtracted. Weißbach [14-16] defined fermentation coefficients based on feeding experiments with sheeps where FOM of the substrates was derived from a correlation between fiber content in substrate and fiber content in the excrements [13-17].

In contrast to the aforementioned specific considerations of the biological anaerobic process, in industrial energy conversion processes the energy output is simply related to the calorific value of the substrate, representing the total energy content $(\mathrm{tE})$. To compare the efficiency of the biogas process with other industrial conversion processes, two methods were developed to consider the non-fermentable fraction of the substrates. Mächtig et al. [18] suggested subtracting the energy of the lignin fraction from the gross energy content, as lignin is the largest non-biodegradable fraction in the feedstock and called this the anaerobically degradable energy (adE). However, the method does not take into account that besides lignin, the encrusted parts of hemicellulose and cellulose are also inaccessible to microorganisms. Moreover, the authors reported a relative high error of prediction of the lignin content by this method. Alternatively, Fischer et al. [19] proposed to correct the calorific value by the fermentation coefficient from the FOM methodology to calculate the energy content of the fermentable organic dry matter (EFOM). Herein, the non-degradable part of the substrate is assumed to be lignin.

Although biological efficiency is very important for optimizing biogas plants, there are only few scientific publications on this topic and there is no comparative study of the presented evaluation methods for calculating the yield and conversion efficiency of the biological process in large-scale BPs, nor is there a systematic analysis on their validity.

A state-supported monitoring program with 33 participating full-scale biogas plants has now provided the first opportunity for this research. The aim of this study was to compare different methods of evaluating efficiency in order to identify the most suitable method. Especially, the differences in methodology and accuracy of data collection as well as the problems in transferring laboratory data to full-scale agricultural BPs are included in the consideration. 


\section{Materials and Methods}

\subsection{Study Design}

In this study, 33 full-scale agricultural BPs in Germany were investigated in the years 2016-2018 for the efficiency of their digestion processes. The descriptive process data of the BPs such as temperature in the first digester, hydraulic retention time (HRT) in heated and gas tight system, the organic loading rate (OLR) and the feed ratio of manure, are listed in Table 1, the substrate ratio of feeding is listed in Table S1. The 33 BPs are a selection from $61 \mathrm{BPs}$ from the biogas measurement program III [20], for which mass and energy balances could be calculated consistently according to the procedure described below. All examined BPs utilize the produced biogas in CHP units exclusively. The average electrical power varied from $73 \mathrm{~kW}$ to $1796 \mathrm{~kW}$, calculated by dividing the accumulated amount of electricity generated during the year under investigation by $8760 \mathrm{~h}$. Different methods were applied to quantify the initial potential for biogas formation of the substrates as well as of the residual potential of the digestates to every BP. All methods are based on a common mass balance. Mass balances were calculated based on monthly values of the material flows. Efficiency indicators were calculated as yearly values based on the sum of the monthly values from mass balances.

Table 1. Average electrical power production, temperature of the first digester, number of hydrolysis stages (HY), primary digesters (FD), secondary digesters (SD) and storage tanks (ST), hydraulic retention time (HRT), organic loading rate (OLR), manure share of the 33 investigated biogas plants (BP). BP 12 is a research biogas plant with high measurement accuracy.

\begin{tabular}{|c|c|c|c|c|c|c|c|}
\hline BP & $\begin{array}{c}\text { Average } \\
\text { Electrical Power }\end{array}$ & $\begin{array}{l}\text { Temperature } \\
\text { First Digester }\end{array}$ & Stages & $\begin{array}{c}\text { HRT } \\
\text { Heated }\end{array}$ & $\begin{array}{c}\text { HRT } \\
\text { Gas-Tight }\end{array}$ & OLR & $\begin{array}{c}\text { Manure } \\
\text { Share }\end{array}$ \\
\hline & kW & ${ }^{\circ} \mathrm{C}$ & HY/FD/SD/ST & d & d & $\mathrm{kg}_{\text {ODM }} \mathrm{d}^{-1} \mathrm{~m}^{-3}$ & $\%$ mass \\
\hline 1 & 73 & 42 & $0 / 1 / 0 / 1$ & 50 & 153 & 3.0 & 91.4 \\
\hline 2 & 532 & $27-33$ & $1 / 1 / 1 / 4$ & 73 & 73 & 2.2 & 75.5 \\
\hline 3 & 74 & 44 & $0 / 1 / 1 / 1$ & 148 & 148 & 1.1 & 81.9 \\
\hline 4 & 671 & $36-40$ & $0 / 1 / 2 / 1$ & 231 & 275 & 1.0 & 36.4 \\
\hline 5 & 1229 & 45 & $0 / 1 / 1 / 2$ & 72 & 213 & 3.3 & 58.0 \\
\hline 6 & 77 & 42 & $0 / 1 / 0 / 1$ & 73 & 221 & 1.9 & 82.1 \\
\hline 7 & 498 & 44 & $0 / 1 / 1 / 2$ & 127 & 346 & 3.4 & 32.9 \\
\hline 8 & 209 & 43 & $0 / 1 / 0 / 2$ & 66 & 66 & 4.9 & 10.5 \\
\hline 9 & 316 & $38-47$ & $0 / 1 / 1 / 2$ & 104 & 156 & 3.1 & 37.7 \\
\hline 10 & 358 & 42 & $0 / 1 / 1 / 1$ & 225 & 225 & 1.6 & 7.7 \\
\hline 11 & 508 & $47-53$ & $0 / 1 / 1 / 1$ & 59 & 116 & 4.8 & 34.9 \\
\hline 12 & 207 & 45 & $0 / 2 / 1 / 0$ & 142 & 142 & 1.8 & 43.6 \\
\hline 13 & 512 & 40 & $0 / 2 / 1 / 2$ & 61 & 61 & 2.6 & 67.9 \\
\hline 14 & 451 & 44 & $0 / 1 / 0 / 1$ & 42 & 168 & 4.9 & 50.9 \\
\hline 15 & 942 & 41 & $0 / 1 / 1 / 1$ & 81 & 81 & 3.8 & 0.3 \\
\hline 16 & 469 & 40 & $0 / 1 / 1 / 1$ & 113 & 113 & 2.3 & 32.5 \\
\hline 17 & 1706 & $43-45$ & $0 / 2 / 1 / 1$ & 72 & 118 & 4.3 & 0.0 \\
\hline 18 & 649 & 45 & $0 / 1 / 1 / 1$ & 133 & 189 & 2.5 & 0.0 \\
\hline 19 & 571 & 43 & $1 / 2 / 0 / 1$ & 63 & 129 & 3.5 & 56.3 \\
\hline 20 & 199 & 39-45 & $0 / 1 / 0 / 1$ & 65 & 134 & 2.5 & 52.9 \\
\hline 21 & 1796 & 43 & $0 / 2 / 1 / 2$ & 73 & 156 & 4.1 & 0.0 \\
\hline 22 & 635 & $43-49$ & $0 / 1 / 1 / 1$ & 71 & 168 & 3.2 & 51.5 \\
\hline 23 & 459 & $52-59$ & $0 / 1 / 1 / 5$ & 101 & 101 & 2.9 & 34.6 \\
\hline 24 & 381 & $35-43$ & $0 / 1 / 0 / 1$ & 78 & 78 & 2.2 & 51.6 \\
\hline 25 & 560 & 43 & $0 / 1 / 1 / 2$ & 89 & 218 & 1.9 & 55.9 \\
\hline 26 & 712 & 42 & $0 / 1 / 0 / 1$ & 54 & 104 & 3.1 & 75.6 \\
\hline 27 & 739 & 43 & $0 / 1 / 1 / 1$ & 124 & 192 & 2.5 & 0.0 \\
\hline 28 & 557 & 44 & $0 / 2 / 0 / 6$ & 45 & 45 & 3.6 & 73.0 \\
\hline 29 & 371 & 43 & $0 / 1 / 1 / 1$ & 87 & 208 & 2,3 & 42.7 \\
\hline 30 & 515 & 42 & $0 / 1 / 0 / 1$ & 81 & 226 & 3.6 & 32.0 \\
\hline 31 & 511 & 42 & $1 / 2 / 1 / 1$ & 120 & 120 & 1.4 & 62.1 \\
\hline 32 & 512 & 44 & $0 / 1 / 1 / 1$ & 61 & 96 & 1.6 & 84.9 \\
\hline 33 & 975 & 50 & $0 / 1 / 2 / 2$ & 59 & 272 & 4.3 & 51.7 \\
\hline
\end{tabular}




\subsection{Data Collection and Laboratory Analyses}

\subsubsection{Process Data}

For calculation of the different efficiency indicators, process data of the examined $\mathrm{BP}$ were necessary. These were recorded automatically from sensors by process control systems or manually by plant operators.

The input mass of every solid substrate was weighed daily by scales. The input volume of every liquid substrate was measured daily via flowmeters or calculated based on livestock units. The concentration of methane in the produced biogas was measured mostly continuously but at least monthly. Operating hours and produced electricity from CHP units was recorded monthly, as well as the feed-in amount of electricity and the amount of internal electricity consumption of the BP. For pilot injection CHP engines, the amount of consumed ignition oil was recorded monthly.

\subsubsection{Sampling}

The input substrate and digestate material streams had to be characterized for their inherent methane and energy potentials by laboratory analysis. Therefore, sampling of these materials was necessary. The sampling method was standardized. Samples of input substrates were taken monthly. Solid substrates were sampled from silos or piles by taking subsamples at $20 \mathrm{~cm}$ depth from different positions and mixing them together. Liquid samples, e.g., manure, were taken after complete mixing of storage tanks. Digestate samples were taken at the last gas-tight digester in flow direction at least every three months. A minimum of $10 \mathrm{~L}$ of the digestate were discarded before taking samples from sampling pipes. Afterwards, the samples were cooled down to $2^{\circ} \mathrm{C} \pm 5^{\circ} \mathrm{C}$ on field-site and stored at $-20^{\circ} \mathrm{C} \pm 1{ }^{\circ} \mathrm{C}$ in the laboratory except for digestate samples for BMP test. These samples were cooled down to $4 \mathrm{C} \pm 1{ }^{\circ} \mathrm{C}$ on field-site and stored at the same temperature in the laboratory.

\subsubsection{Dry Matter Content (DM) and Organic Dry Matter Content (ODM)}

DM and ODM were analyzed for every sample at least in duplicate according to German standards DIN EN 15935 [21]. The DM and ODM of all silage and sugar beet samples were corrected for volatile fatty acids according to Weißbach et al. [13-15]. The $\mathrm{pH}$ values and acid concentrations were measured in duplicate for the DM/ODM correction of silages and sugar beet. More information about the measurement methods can be found in the literature [22-24].

\subsubsection{Biochemical Methane Potential Test}

The biochemical methane potential (BMP) test was done in three different laboratories, two of them used the Hohenheim biogas yield test (HBT). HBT is a continuous mixed system with a $100 \mathrm{~mL}$-syringe as the reactor. The determination of the methane percentage was done by an infrared-spectrometric methane-sensor Advanced Gasmitter, Pronova Analysetechnik (Berlin, Germany). Between both HBTs only the methane quality measurement was different. BP 5-17 and 24-32 were measured in dry gas and BP 1-4 and 20-23 were measured in wet gas and corrected afterwards. The third laboratory used a Bergedorf fermentation test [9] with a volume of 1.5 $\mathrm{L}$ and measured the BP 18-19 and 33. Gas was measured by a tipping cell counter (MilligasCounter, Ritter Apparatebau GmbH, Bochum, Germany). Methane percentage was measured by an infrared sensor (Awite Bioenergie $\mathrm{GmbH}$, Langenbach, Germany).

The BMP test of all substrate samples was done once year for all substrates according to VDI 4630 [9]. Temperature for all tests was $37^{\circ} \mathrm{C}$ and the tests stopped, for HBTs, after 35 days and for Bergedorf fermentation after reaching less than $0.5 \%$ total methane production in one day. All samples were measured at least in triplicates and with an inoculum to substrate ODM ratio of 2:1. Inocula from a $400 \mathrm{~L}$ laboratory reactor was used to investigate samples from BP 5-17 and 24-32, inocula from a wastewater treatment plant to investigate samples from BP 1-4 and 20-23 and inocula from $2500 \mathrm{~L}$ reactor to investigate 
samples from BP 18-19 and 33. Hülsemann et al. [11] describes in detail the systems, the inocula and the measurement accuracy. The specific methane potential of the digestate was measured according to $\mathrm{VdLuFa}[25]$ at $37^{\circ} \mathrm{C}$ for 60 days.

\subsubsection{Fiber Content}

The raw fiber content of biomass in general describes the organic, non-fat, acidand alkali-insoluble fraction and was determined for FOM calculation. Raw fiber was determined according to the protocol published by Dittrich-Zechendorf [26]. The fat free sample material was successively treated in boiling sulphuric acid and caustic potash of a defined concentration. The remainder is separated, dried, weighed and finally incinerated at $500{ }^{\circ} \mathrm{C}$. The loss of mass during incineration corresponds to the raw fiber content of the sample. The fiber content of each of the BP's substrates was analyzed four times a year and in triplicates for statistical validation.

\subsubsection{Gross Calorific Value}

The gross calorific value (GCV) was determined according to DIN EN ISO 18125 [27]. A correction for sulfur or nitrogen content was omitted. The samples were dried at $105^{\circ} \mathrm{C}$ and milled to a particle size smaller than $1 \mathrm{~mm}$ prior to analysis. This way, dry matter specific GCVs were measured. The GCV was corrected for volatile fatty acids and alcohols, like done in DM determination for silage samples. For the substrate and digestate of each $\mathrm{BP}$, the gross calorific value was determined four times in a year in triplicates.

\subsection{Mass Balance}

The system boundary for mass balances was chosen to enclose all gas-tight digesters (Figure 1) in order to describe the biological process alone and also be independent of the $\mathrm{BP}^{\prime} \mathrm{s}$ biogas conversion technologies [28]. For mass balances all material streams crossing the system boundary were determined.

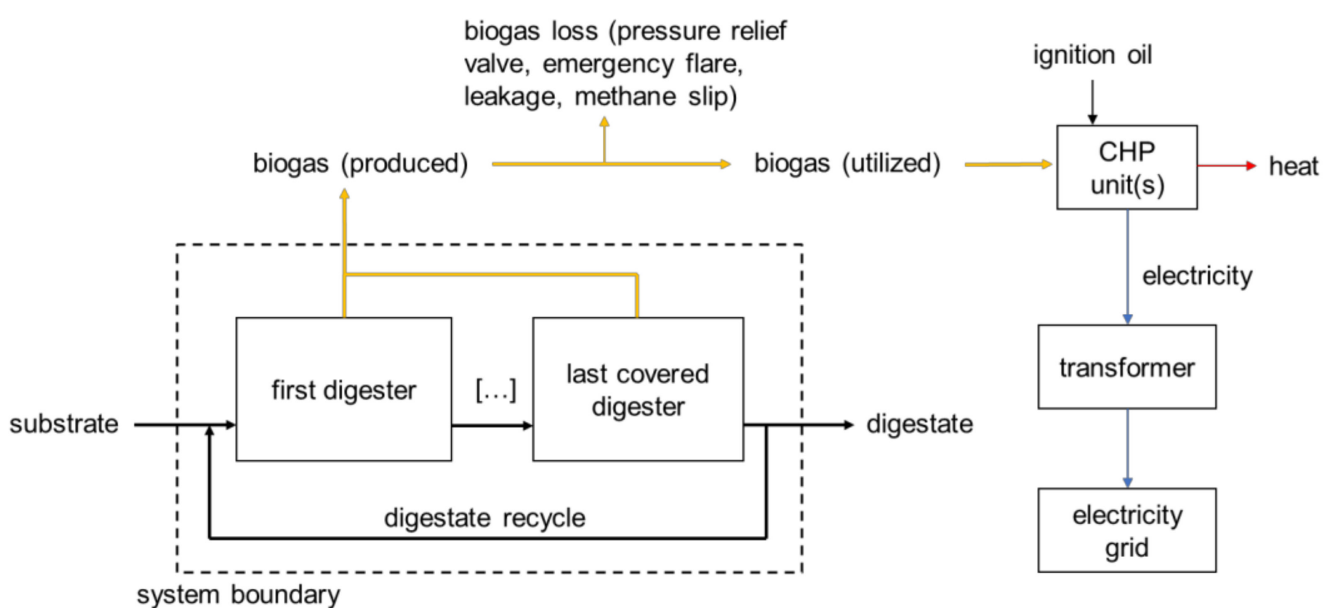

Figure 1. System boundary for efficiency assessment; starting with the first digester and ending with the last covered digester ( $\mathrm{CHP}$ — combined heat and power plant).

All examined BPs performed a continuous digestion process. Feeding intervals were between $20 \mathrm{~min}$ and $1 \mathrm{~h}$. Fluctuating liquid filling levels in covered digestate storage tanks, due to agricultural logistics in digestate application, were handled by choosing an investigation period of 12 months. This way, seasonal variations during the observation period were reduced. Therefore, steady state conditions were assumed. Based on the defined system boundary, three material streams had to be considered in the mass balance: substrate, biogas and digestate. Recycled digestate was not considered in the balance, since it is not leaving the system boundary (Figure 1). In case of solid-liquid-separation prior to recycling of the liquid digestate, both fractions were considered in the mass balance. 
The following equation was used for steady-state mass balancing:

$$
\Delta \mathrm{m}=0=\mathrm{m}_{\mathrm{sub}}-\mathrm{m}_{\mathrm{gas}}-\mathrm{m}_{\mathrm{dig}}
$$

where $m_{\text {sub }}$ is the mass of the substrate, $m_{\text {gas }}$ the mass of the biogas and $m_{\text {dig }}$ the mass of the digestate.

\subsubsection{Substrate}

The masses and/or flow rates of substrate input were measured at every BP. Liquid substrate intake was measured or calculated as flow rate and converted to mass assuming a density of $1000 \mathrm{~kg} \mathrm{~m}^{-3}$ due to the high water contents (more than $90 \%$ ).

\subsubsection{Biogas}

Measurement equipment for biogas flow is rarely available at the examined agricultural biogas plants. In order to apply a common procedure, the amount of utilized biogas was assumed to be equal to the produced amount of biogas, which was based on the amount of electricity, which was fed into the grid. This value was measured and recorded by grid operators and is the only reliable value that is available for each of the BP. Losses by biogas leakages in pipes, digester roofs or pressure relief valves were not measured and could therefore not be considered.

For the calculation of produced biogas, the following assumptions were made:

- the transformation loss between the feed-in point and the CHP unit is $2 \%$ of the amount of electricity fed in, which is the average value of all examined BPs for which this transformation loss could be calculated based on alignment of electricity measurement at CHP units and at the grid access point;

- $\quad$ gas leakages and losses, like gas burned in the emergency flares, were not considered;

- for BPs using more than one CHP unit: The fed-in electricity from the BP was allocated to single CHP units by their rated power and operating hours in the investigated 12-month period;

- the electrical efficiency of CHP units was assumed to be equal to the published values by the manufacturers minus 3.1\%, which reflects the average efficiency loss as determined by Aschmann and Effenberger [29]. Factors for efficiency loss are engine wear, site of installation above sea level, properties at different loads and engine settings. A higher accuracy in this value was not possible with the available data;

- the biogas was simplified to consist of methane and carbon dioxide only. The methane concentration was measured at every BP at least one time a month. The residual was assumed to be carbon dioxide only. Justification: Water vapor in produced biogas was condensed by gas cooling at every BP. The condensed water was pumped into digestate storage tanks and accounts to digestate mass in the mass balance. Other trace gas components produce a negligible error.

The gross electrical energy produced by the CHP units of a BP was calculated by:

$$
\mathrm{W}_{\text {gross }}=1.02 \times \mathrm{W}_{\text {grid }}+\mathrm{W}_{\mathrm{oc}}
$$

where $W_{\text {gross }}$ gross electricity, $W_{\text {grid }}$ electricity feed in grid and $W_{O C}$ is the amount of produced electricity which is used internally by the BP. 31 of the examined biogas plants inject the total produced electricity, so that $W_{O C}$ equals zero in these cases.

For BPs with more than one CHP unit, the ratio $a_{k}$ of the electricity produced by a single CHP k was calculated by:

$$
a_{k}=\frac{t_{k} \times P_{k}}{\sum_{k} t_{k} \times P_{k}}
$$


The energy of utilized biogas in all CHP units of a BP was calculated by:

$$
\mathrm{E}_{\text {gas }}=\sum_{\mathrm{k}} \frac{\mathrm{a}_{\mathrm{k}}}{\left(\eta_{\mathrm{k}}-0.031\right)} \times \mathrm{W}_{\text {gross }}
$$

with $\eta_{\mathrm{k}}$ the electrical efficiency of the CHP units.

The utilized volume of biogas was calculated by:

$$
\mathrm{V}_{\text {gas }}=\frac{\mathrm{E}_{\text {gas }}-\mathrm{W}_{\mathrm{PIO}}}{\mathrm{NCV}_{\mathrm{CH}_{4}} \times \mathrm{x}_{\mathrm{CH}_{4}}}
$$

where $\mathrm{NCV}_{\mathrm{CH}_{4}}$ the net calorific value, $\mathrm{x}_{\mathrm{CH}_{4}}$ the methane ratio and $\mathrm{W}_{\mathrm{PIO}}$ the amount of energy from ignition oil, which was subtracted for BPs, which used pilot injection engines as CHP. Finally, the mass of biogas was calculated by:

$$
\mathrm{m}_{\text {gas }}=\mathrm{V}_{\text {gas }} \times\left[\mathrm{x}_{\mathrm{CH} 4} \times \rho_{\mathrm{CH} 4}+\left(1-\mathrm{x}_{\mathrm{CH} 4}\right) \times \rho_{\mathrm{CO} 2}\right]
$$

With the densities $\rho_{\mathrm{CH} 4}=0.72 \mathrm{~kg} \mathrm{~m}^{-3}$ and $\rho_{\mathrm{CO} 2}=1.98 \mathrm{~kg} \mathrm{~m}^{-3}$ at temperature of $0{ }^{\circ} \mathrm{C}$ and pressure of $101,325 \mathrm{kPa}$

Relating the utilized volume of biogas to the amount of ODM of fed substrate in the same timespan leads to the on-site specific methane yield (SMY):

$$
\text { On-site SMY }=\frac{\mathrm{V}_{\text {gas }}}{\mathrm{m}_{\text {sub,ODM }}}
$$

\subsubsection{Digestate}

The mass and volume of digestate was not recorded at the examined BPs and therefore for the calculation using the mass balance:

$$
\mathrm{m}_{\text {dig }}=\mathrm{m}_{\text {sub }}-\mathrm{m}_{\text {gas }}
$$

\subsubsection{Organic Dry Matter Content (ODM) Material Balance}

An ODM material balance was used to evaluate the plausibility of the mass balance. Mass of ODM for each substrate, gas and digestate (i) was calculated for each month $j=1$, $\ldots, 12$ and summed up for the year.

Two cases were investigated. First, it was assumed, that biogas was produced from ODM only. Second, water incorporation of $10 \%$ of the mass of biogas was considered, originating from cellulose degradation during digestion.

Evaluation was done by calculating the ODM balance residual (ODMBR) in the following equation:

$\operatorname{ODMBR}(\%)=\frac{\sum_{\text {sub i }} \sum_{\mathrm{j}} \mathrm{m}_{\text {sub,i,j }} \times \operatorname{DM}_{\mathrm{i}, \mathrm{j}} \times \mathrm{ODM}_{\mathrm{i}, \mathrm{j}}-\sum_{\mathrm{j}} \mathrm{m}_{\mathrm{gas}, \mathrm{j}} \times\left(1-\mathrm{w}_{\mathrm{H} 2 \mathrm{O}}\right)-\sum_{\text {dig }} \mathrm{g} \sum_{\mathrm{j}} \mathrm{m}_{\mathrm{dig}, \mathrm{g}, \mathrm{j}} \times \mathrm{DM}_{\mathrm{g}, \mathrm{j}} \times \mathrm{ODM}_{\mathrm{g}, \mathrm{j}}}{\sum_{\text {sub i }} \sum_{\mathrm{j}} \mathrm{m}_{\text {sub,i,j }} \times \mathrm{DM}_{\mathrm{i}, \mathrm{j}} \times \mathrm{ODM}_{\mathrm{i}, \mathrm{j}}}$

where $\mathrm{w}_{\mathrm{H} 2 \mathrm{O}}=0.1$ for $10 \%$ water incorporation or $\mathrm{w}_{\mathrm{H} 2 \mathrm{O}}=0$ for neglecting water incorporation.

\subsection{Energy Balance}

The system boundary for energy and energy balances was chosen equal to the one for mass balance (Figure 1). Energy flows associated with mass flows were examined to evaluate energy-based efficiency indicators as well as to prove the plausibility of the used process data for mass balancing. According to the defined system boundary the only mass associated energy intake is the substrate input. Energy outputs are biogas and digestate. The residual of the input energy leaves the process as a loss of heat and entropy as a result of the conversion process of the organic matter. 
The following balance was applied to calculate the part of the substrate energy, which is lost in the digestion process as heat, entropy or leakage of biogas:

$$
\mathrm{E}_{\text {loss }}=\mathrm{E}_{\text {substrate }}-\mathrm{E}_{\text {digestate }}-\mathrm{E}_{\text {gas }}
$$

$E_{\text {substrate }}$ is the potential of the substrate fed in a BP as input. $E_{\text {digestate }}$ is the potential of the digestate as output, $E_{\text {gas }}$ is the potential of produced biogas and $E_{\text {loss }}$ is the potential lost during the process (e.g., burned gas by emergency flare, leakage, open pressure relief valve, heat loss) (Equation (10)).

The energy balance residual (EBR), was calculated as:

$$
\begin{aligned}
& \operatorname{EBR}(\%)=
\end{aligned}
$$

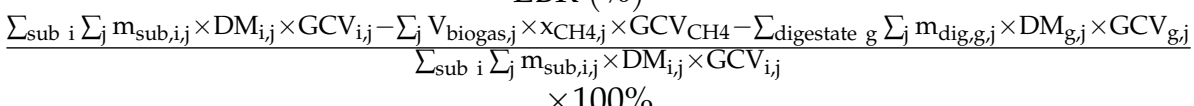

\subsection{Specific Methane Potential of Substrate Mixtures}

Six different methods were used to calculate the annual average ODM-specific methane potential (SMP) of the fed substrate mixtures of the $33 \mathrm{BPs}$. The formulas represent the ODM-weighted average of the SMP of the single substrates used. For methods based on energy quantities, the SMP was calculated by simply dividing the energy amount by the GCV of methane. By that, conversion losses are neglected.

\subsubsection{Biochemical Methane Potential Test (BMP)}

The BMP is a batch test, with which the specific methane potential of the substrate can be measured directly. The mixture from direct BMP measurements was calculated by:

$$
\mathrm{SMP}_{\mathrm{BMP}, \mathrm{SM}}=\frac{\sum_{\text {sub i }} \sum_{\mathrm{j}} \mathrm{m}_{\text {sub }, \mathrm{i}, \mathrm{j}} \times \mathrm{DM}_{\mathrm{i}, \mathrm{j}} \times \mathrm{ODM}_{\mathrm{i}, \mathrm{j}} \times \mathrm{SMP}_{\mathrm{BMP}, \mathrm{i}}}{\sum_{\text {sub i }} \sum_{\mathrm{j}} \mathrm{m}_{\text {sub }, \mathrm{i}, \mathrm{j}} \times \mathrm{DM}_{\mathrm{i}, \mathrm{j}} \times \mathrm{ODM}_{\mathrm{i}, \mathrm{j}}}
$$

\subsubsection{Values According to Literature (KTBL)}

The specific methane potential of the substrate mixture using KTBL values from literature was calculated by:

$$
\mathrm{SMP}_{\mathrm{KTBL}, \mathrm{SM}}=\frac{\sum_{\text {sub i }} \sum_{\mathrm{j}} \mathrm{m}_{\text {sub }, \mathrm{i}, \mathrm{j}} \times \mathrm{DM}_{\mathrm{i}, \mathrm{j}} \times \mathrm{ODM}_{\mathrm{i}, \mathrm{j}} \times \mathrm{SMP}_{\mathrm{KTBL}, \mathrm{i}}}{\sum_{\text {sub i }} \sum_{\mathrm{j}} \mathrm{m}_{\text {sub }, \mathrm{i}, \mathrm{j}} \times \mathrm{DM}_{\mathrm{i}, \mathrm{j}} \times \mathrm{ODM}_{\mathrm{i}, \mathrm{j}}}
$$

$\mathrm{SMP}_{\mathrm{KTBL}, \mathrm{i}}$ is the SMP of a single substrate $\mathrm{i}$ from the KTBL- values, which are based on the results of biochemical methane potential test and are given for the most common agricultural substrates in Germany [12]. For rarely used substrates, for which KTBL values were not defined, $\mathrm{SMP}_{\mathrm{BMP}, \mathrm{i}}$ values were used.

\subsubsection{Fermentable Organic Dry Matter (FOM)}

The FOM is a part of ODM, according to Equation (14). FOM considers that not all of the ODM can be anaerobically degraded. Calculation is done by subtracting a part of the fiber content from ODM, which is a substrate specific calculation of the so called fermentation coefficient $f_{i}$ based on regression equations investigated by fermentation experiments in sheep stomach [13]. For manure, fermentation coefficients were defined based on BMP results $[15,16]$.

$$
\mathrm{FOM}_{\mathrm{i}}=\mathrm{f}_{\mathrm{i}} \times \mathrm{ODM}_{\mathrm{i}}
$$

The specific methane potential of the substrate mixture based on FOM was calculated by:

$$
\mathrm{SMP}_{\mathrm{FOM}, \mathrm{SM}}=\frac{\sum_{\text {sub i }} \sum_{\mathrm{j}} \mathrm{m}_{\text {sub }, \mathrm{i}, \mathrm{j}} \mathrm{DM}_{\mathrm{i}, \mathrm{j}} \times \mathrm{FOM}_{\mathrm{i}, \mathrm{j}} \times \mathrm{SMP}_{\mathrm{avFOM}}}{\sum_{\text {sub i }} \sum_{\mathrm{i}} \mathrm{m}_{\text {sub }, \mathrm{i}, \mathrm{j}} \times \mathrm{DM}_{\mathrm{i}, \mathrm{j}} \times \mathrm{ODM}_{\mathrm{i}, \mathrm{j}}}
$$


$\mathrm{SMP}_{\mathrm{avFOM}}$ is the average specific methane potential of FOM, which is used as a constant factor according to Weißbach [13] (Equation (16)).

$$
\mathrm{SMP}_{\mathrm{avFOM}}=420 \mathrm{~L} \mathrm{~kg}^{-1}
$$

For substrates without a regression equation by Weißbach [13-17], the fermentation coefficient $\mathrm{f}$ was calculated. The $\mathrm{SMP}_{\mathrm{BMP}, \mathrm{i}}$ was used to determine the fermentation coefficient for FOM calculation by:

$$
\mathrm{f}_{\mathrm{i}}=\frac{\mathrm{SMP}_{\mathrm{BMP}, \mathrm{i}}}{\mathrm{SMP}_{\mathrm{avFOM}}}
$$

\subsubsection{Energy of Fermentable Organic Dry Matter (EFOM)}

With EFOM, the FOM is considered energetically by measuring the gross calorific value of ODM and distinguishing degradable and non-degradable fraction using the fermentation coefficient from FOM-methodology according to Fischer et al. [19]. Herein, the non-degradable fraction is assumed to be lignin.

The specific methane potential of the substrate mixture based on the energy of FOM was calculated by:

$$
\mathrm{SMP}_{\mathrm{EFOM}, \mathrm{SM}}=\frac{\sum_{\text {sub i }} \sum_{\mathrm{j}} \mathrm{m}_{\text {sub }, \mathrm{i}, \mathrm{j}} \times \mathrm{DM}_{\mathrm{i}, \mathrm{j}} \times \mathrm{ODM}_{\mathrm{i}, \mathrm{j}} \times \mathrm{GCV}_{\mathrm{FOM}, \mathrm{i}, \mathrm{j}}}{\sum_{\text {sub i }} \sum_{\mathrm{j}} \mathrm{m}_{\text {sub }, \mathrm{i}, \mathrm{j}} \times \mathrm{DM}_{\mathrm{i}, \mathrm{j}} \times \mathrm{ODM}_{\mathrm{i}, \mathrm{j}} \times \mathrm{GCV}_{\mathrm{CH} 4}}
$$

$\mathrm{GCV}_{\mathrm{FOM}, \mathrm{i}, \mathrm{j}}$ is the gross calorific value of FOM, calculated according to equation 7 of Fischer et al. [19]. The gross calorific value of methane $\mathrm{GCV}_{\mathrm{CH} 4}$ was assumed to be $39.73 \mathrm{MJ} \mathrm{m}^{-3}[30]$.

\subsubsection{Anaerobically Degradable Energy (adE)}

The adE is the energy of anaerobically degradable parts of ODM, which is calculated by subtracting the energy of lignin from tE. In contradiction to EFOM methodology, the non-degradable part of ODM is not calculated using fermentation coefficients, but by estimating the lignin content of digestates from measured gross calorific values of the digestates. As lignin is assumed to be non-degradable, the energy of lignin in the substrate mixtures has to be the same amount as in the respective digestates.

The specific methane potential of the substrate mixture using the anaerobically degradable energy content was calculated by:

$\mathrm{SMP}_{\mathrm{adE}, \mathrm{SM}}=\frac{\sum_{\text {sub i }} \sum_{\mathrm{j}} \mathrm{m}_{\text {sub }, \mathrm{i}, \mathrm{j}} \times \mathrm{DM}_{\mathrm{i}, \mathrm{j}} \times \mathrm{GCV}_{\mathrm{i}, \mathrm{j}}-\sum_{\text {dig g }} \sum_{\mathrm{j}} \mathrm{m}_{\text {dig,g,j }} \times \mathrm{DM}_{\mathrm{g}, \mathrm{j}} \times \mathrm{ODM}_{\mathrm{g}, \mathrm{j}} \times \mathrm{w}_{\text {lig,g, }} \times \mathrm{GCV}_{\text {lig }}}{\sum_{\text {sub i }} \sum_{\mathrm{j}} \mathrm{m}_{\text {sub }, \mathrm{i}, \mathrm{j}} \times \mathrm{DM}_{\mathrm{i}, \mathrm{j}} \times \mathrm{ODM}_{\mathrm{i}, \mathrm{j}} \times \mathrm{GCV}_{\mathrm{CH} 4}}$

The lignin content $\mathrm{w}_{\text {lig }}$ in digestate was calculated from measured gross calorific values of the digestate according to the regression equation M1 by Mächtig et al. [18]. The authors stated a gross calorific value of lignin of $33.74 \mathrm{MJ} \mathrm{kg}^{-1}$ for this model, which was used here for $\mathrm{GCV}_{\text {lig. }}$.

\subsubsection{Total Energy (tE)}

The total energy content is calculated from measured gross calorific values and does not consider the different anaerobic degradability of substrates. The specific methane potential of the substrate mixture using the total energy content was calculated by:

$$
\mathrm{SMP}_{\mathrm{tE}, \mathrm{SM}}=\frac{\sum_{\text {sub i }} \sum_{\mathrm{j}} \mathrm{m}_{\text {sub,i,j }} \times \mathrm{DM}_{\mathrm{i}, \mathrm{j}} \times \mathrm{GCV}_{\mathrm{i}, \mathrm{j}}}{\sum_{\text {sub i }} \sum_{\mathrm{j}} \mathrm{m}_{\text {sub }, \mathrm{i}, \mathrm{j}} \times \mathrm{DM}_{\mathrm{i}, \mathrm{j}} \times \mathrm{ODM}_{\mathrm{i}, \mathrm{j}} \times \mathrm{GCV}_{\mathrm{CH} 4}}
$$




\subsection{Efficiency Indicators}

\subsubsection{Yield Efficiency}

The yield efficiency (YE) is an efficiency indicator, which describes which part of the initial potential of the input was converted to the desired output of methane.

$$
\mathrm{YE}=\frac{\text { amount of produced methane }}{\text { methane potential of input substrate }}
$$

The numerator can either be the mass of methane or the energy of methane. The denominator, which represents the initial potential, has consequently to be given in the same dimension. YE was calculated using different methods to quantify the methane or energy potential.

\section{Yield Based on BMP}

The YE based on biochemical methane potential tests $\mathrm{YE}_{\mathrm{BMP}}$ was calculated as follows:

$$
\mathrm{YE}_{\mathrm{BMP}}=\frac{\sum_{\text {month } \mathrm{j}} \mathrm{V}_{\text {gas }, \mathrm{j}} \times \mathrm{x}_{\mathrm{CH} 4, \mathrm{j}}}{\sum_{\text {sub i }} \sum_{\mathrm{j}} \mathrm{m}_{\text {sub }, \mathrm{i}, \mathrm{j}} \times \mathrm{DM}_{\mathrm{i}, \mathrm{j}} \times \mathrm{ODM}_{\mathrm{i}, \mathrm{j}} \times \mathrm{SMP}_{\mathrm{BMP}, \mathrm{i}}}
$$

Yield Based on KTBL

The YE based on KTBL- values $\mathrm{YE}_{\mathrm{KTBL}}$ was calculated as follows:

$$
\mathrm{YE}_{\mathrm{KTBL}}=\frac{\sum_{\text {month } \mathrm{j}} \mathrm{V}_{\text {gas }, \mathrm{j}} \times \mathrm{x}_{\mathrm{CH} 4, \mathrm{j}}}{\sum_{\text {sub } \mathrm{i}} \sum_{\mathrm{j}} \mathrm{m}_{\mathrm{sub}, \mathrm{i}, \mathrm{j}} \times \mathrm{DM}_{\mathrm{i}, \mathrm{j}} \times \mathrm{ODM}_{\mathrm{i}, \mathrm{j}} \times \mathrm{SMP}_{\mathrm{KTBL}, \mathrm{i}}}
$$

$\mathrm{SMP}_{\mathrm{KTBL}, \mathrm{i}}$ is the specific methane potential (SMP) from the KTBL- values [12]. Where KTBL values were not defined, $\mathrm{SMP}_{\mathrm{BMP}, \mathrm{i}}$ values were used.

\section{Yield Based on FOM}

The YE based on methane potential of fermentable organic dry matter content $\mathrm{YE}_{\mathrm{FOM}}$ was calculated as follows:

$$
\mathrm{YE}_{\mathrm{FOM}}=\frac{\sum_{\text {month } \mathrm{j}} \mathrm{V}_{\text {gas }, \mathrm{j}} \times \mathrm{x}_{\mathrm{CH} 4, \mathrm{j}}}{\sum_{\text {sub i }} \sum_{\mathrm{j}} \mathrm{m}_{\text {sub }, \mathrm{i}, \mathrm{j}} \times \mathrm{DM}_{\mathrm{i}, \mathrm{j}} \times \mathrm{FOM}_{\mathrm{i}, \mathrm{j}} \times \mathrm{SMP}_{\mathrm{FOM}}}
$$

\section{Yield Based on EFOM}

The YE based on the energy of fermentable organic dry matter $\mathrm{YE}_{\mathrm{EFOM}}$ was calculated as follows:

$$
\mathrm{YE}_{\mathrm{EFOM}}=\frac{\sum_{\text {month } \mathrm{j}} \mathrm{V}_{\text {gas, } \mathrm{j}} \times \mathrm{x}_{\mathrm{CH} 4, \mathrm{j}} \times \mathrm{GCV}_{\mathrm{CH} 4}}{\sum_{\text {sub i }} \sum_{\mathrm{j}} \mathrm{m}_{\text {sub }, \mathrm{i}, \mathrm{j}} \times \mathrm{DM}_{\mathrm{i}, \mathrm{j}} \times \mathrm{ODM}_{\mathrm{i}, \mathrm{j}} \times \mathrm{GCV}_{\mathrm{FOM}, \mathrm{i}, \mathrm{j}}}
$$

Yield Based on adE

The YE based on the energy of anaerobically degradable part of the substrate $\mathrm{YE}_{\mathrm{adE}}$ was calculated as follows:

$$
\mathrm{YE}_{\mathrm{adE}}=\frac{\sum_{\text {month } \mathrm{j}} \mathrm{V}_{\text {gas }, \mathrm{j}} \times \mathrm{x}_{\mathrm{CH} 4, \mathrm{j}} \times \mathrm{GCV}_{\mathrm{CH} 4}}{\sum_{\text {sub } \mathrm{i}} \sum_{\mathrm{j}} \mathrm{m}_{\mathrm{sub}, \mathrm{i}, \mathrm{j}} \times \mathrm{DM}_{\mathrm{i}, \mathrm{j}} \times \mathrm{GCV}_{\mathrm{i}, \mathrm{j}}-\sum_{\text {dig g }} \sum_{\mathrm{j}} \mathrm{m}_{\text {dig, }, \mathrm{j}, \mathrm{j}} \times \mathrm{DM}_{\mathrm{g}, \mathrm{j}} \times \mathrm{ODM}_{\mathrm{g}, \mathrm{j}} \times \mathrm{w}_{\text {lig, }, \mathrm{j}, \mathrm{j}} \times \mathrm{GCV}_{\text {lig }}}
$$

Yield Based on $\mathrm{tE}$

The $\mathrm{YE}$ based on the total energy of substrate $\mathrm{YE}_{\mathrm{tE}}$ was calculated as follows:

$$
\mathrm{YE}_{\mathrm{tE}}=\frac{\sum_{\text {month } \mathrm{j}} \mathrm{V}_{\text {gas }, \mathrm{j}} \times \mathrm{x}_{\mathrm{CH} 4, \mathrm{j}} \times \mathrm{GCV}_{\mathrm{CH} 4}}{\sum_{\text {sub i }} \sum_{\mathrm{j}} \mathrm{m}_{\text {sub,i, }} \times \mathrm{DM}_{\mathrm{i}, \mathrm{j}} \times \mathrm{GCV}_{\mathrm{i}, \mathrm{j}}}
$$




\subsubsection{Conversion Efficiency}

The conversion efficiency (CE) is an efficiency indicator, which describes which part of the initial potential of the input was converted.

$$
\mathrm{CE}=\frac{\text { potential of input substrate }- \text { potential of the digestate }}{\text { potential of input substrate }}
$$

Different methods were used for the calculation of CE.

\section{Conversion Based on BMP}

The $\mathrm{CE}$ based on biochemical methane potential tests $\mathrm{CE}_{\mathrm{BMP}}$ was calculated as follows:

$\mathrm{CE}_{\mathrm{BMP}}=\frac{\sum_{\text {sub i }} \sum_{\mathrm{j}} \mathrm{m}_{\text {sub }, \mathrm{i}, \mathrm{j}} \times \mathrm{DM}_{\text {sub }, \mathrm{i}, \mathrm{j}} \times \mathrm{ODM}_{\text {sub }, \mathrm{i}, \mathrm{j}} \times \mathrm{SMP}_{\mathrm{BMP}, \mathrm{i}}-\sum_{\text {dig g }} \sum_{\mathrm{j}} \mathrm{m}_{\text {dig, }, \mathrm{j}, \mathrm{j}} \times \mathrm{DM}_{\mathrm{g}, \mathrm{j}} \times \mathrm{ODM}_{\mathrm{g}, \mathrm{j}} \times \mathrm{SMP}_{\mathrm{BMP}, \mathrm{dig}, \mathrm{g}, \mathrm{j}}}{\sum_{\text {sub i }} \sum_{\mathrm{j}} \mathrm{m}_{\text {sub }, \mathrm{i}, \mathrm{j}} \times \mathrm{DM}_{\mathrm{i}, \mathrm{j}} \times \mathrm{ODM}_{\mathrm{i}, \mathrm{j}} \times \mathrm{SMP}_{\mathrm{BMP}, \mathrm{i}}}$

The $\mathrm{SMP}_{\mathrm{BMP} \text {,dig }}$ describe how much gas can be produced out of the digestate by an additional hydraulic retention time of 60 days and $37^{\circ} \mathrm{C}$.

\section{Conversion Based on FOM}

The $\mathrm{CE}$ based on fermentable organic dry matter $\mathrm{CE}_{\mathrm{FOM}}$ was calculated as follows:

$$
\mathrm{CE}_{\mathrm{FOM}}=\frac{\sum_{\text {sub i }} \sum_{\mathrm{j}} \mathrm{m}_{\text {sub }, \mathrm{i}, \mathrm{j}} \times \mathrm{DM}_{\mathrm{i}, \mathrm{j}} \times \mathrm{ODM}_{\mathrm{i}, \mathrm{j}}-\sum_{\text {dig g }} \sum_{\mathrm{j}} \mathrm{m}_{\text {dig,g,j }} \times \mathrm{DM}_{\mathrm{g}, \mathrm{j}} \times \mathrm{ODM}_{\mathrm{g}, \mathrm{j}}}{\sum_{\text {sub i }} \sum_{\mathrm{j}} \mathrm{m}_{\text {sub }, \mathrm{i}, \mathrm{j}} \times \mathrm{DM}_{\mathrm{i}, \mathrm{j}} \times \mathrm{FOM}_{\mathrm{i}, \mathrm{j}}}
$$

Due to missing correlation equations to calculate the residual FOM in the digestate, the amount of degraded organic matter is set as numerator, as by the theory of the method degradation can only occur from FOM.

\section{Conversion Based on EFOM}

The CE based on energy fermentable organic dry matter $\mathrm{CE}_{\mathrm{EFOM}}$ was calculated as follows:

$$
\mathrm{CE}_{\mathrm{EFOM}}=\frac{\sum_{\text {sub i }} \sum_{\mathrm{j}} \mathrm{m}_{\text {sub,i,j }} \times \mathrm{DM}_{\mathrm{i}, \mathrm{j}} \times \mathrm{GCV}_{\mathrm{i}, \mathrm{j}}-\sum_{\text {dig g }} \sum_{\mathrm{j}=1}^{12} \mathrm{~m}_{\text {dig,g,j }} \times \mathrm{DM}_{\mathrm{g}, \mathrm{j}} \times \mathrm{GCV}_{\mathrm{g}, \mathrm{j}}}{\sum_{\text {sub } i} \sum_{\mathrm{j}} \mathrm{m}_{\text {sub }, \mathrm{i}, \mathrm{j}} \times \mathrm{DM}_{\mathrm{i}, \mathrm{j}} \times \mathrm{ODM}_{\mathrm{i}, \mathrm{j}} \times \mathrm{GCV}_{\mathrm{FOM}, \mathrm{i}, \mathrm{j}}}
$$

Due to missing correlation equations to calculate the residual FOM in the digestate and the inherent energy, the amount of converted total energy is set as numerator, as by the theory of this method the converted energy can only be released from degradation of FOM.

Conversion Based on adE

The $C E$ based on the energy of anaerobically degradable part of the substrate $C_{\mathrm{adE}}$ was calculated as follows:

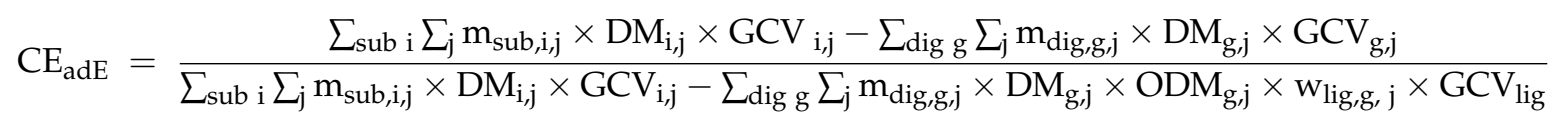

$\mathrm{CE}_{\mathrm{adE}}$ describes the conversion with the assumption that lignin cannot be degraded.

\section{Conversion Based on $\mathrm{tE}$}

The $\mathrm{CE}$ based on total energy $\mathrm{CE}_{\mathrm{tE}}$ was calculated as follows:

$$
\mathrm{CE}_{\mathrm{tE}}=\frac{\sum_{\text {sub i }} \sum_{\mathrm{j}} \mathrm{m}_{\text {sub }, \mathrm{i}, \mathrm{j}} \times \mathrm{DM}_{\mathrm{i}, \mathrm{j}} \times \mathrm{GCV}_{\mathrm{i}, \mathrm{j}}-\sum_{\text {dig g }} \sum_{\mathrm{j}} \mathrm{m}_{\text {dig, }, \mathrm{j}} \times \mathrm{DM}_{\mathrm{g}, \mathrm{j}} \times \mathrm{GCV}_{\mathrm{g}, \mathrm{j}}}{\sum_{\text {sub i }} \sum_{\mathrm{j}} \mathrm{m}_{\text {sub }, \mathrm{i}, \mathrm{j}} \times \mathrm{DM}_{\mathrm{i}, \mathrm{j}} \times \mathrm{GCV}_{\mathrm{i}, \mathrm{j}}}
$$

$\mathrm{GCV}_{\mathrm{g}, \mathrm{j}}$ describes the energy content in the digestate without distinguishing the nondegradable part. 


\section{Conversion Based on ODM}

The CE based on the organic dry matter content of the substrate CEODM was calculated as follows:

$$
\mathrm{CE}_{\mathrm{ODM}}=\frac{\sum_{\text {sub i }} \sum_{\mathrm{j}} \mathrm{m}_{\text {sub,i,j }} \times \mathrm{DM}_{\text {sub, i, } \mathrm{j}} \times \mathrm{ODM}_{\text {sub }, \mathrm{i}, \mathrm{j}}-\sum_{\text {dig g }} \sum_{\mathrm{j}} \mathrm{m}_{\text {dig, }, \mathrm{j}, \mathrm{j}} \times \mathrm{DM}_{\text {dig,g,j }} \times \mathrm{ODM}_{\text {dig,g,j }}}{\sum_{\text {sub i }} \sum_{\mathrm{j}} \mathrm{m}_{\text {sub }, \mathrm{i}, \mathrm{j}} \times \mathrm{DM}_{\mathrm{i}, \mathrm{j}} \times \mathrm{ODM}_{\mathrm{i}, \mathrm{j}}}
$$

\section{Results and Discussion}

\subsection{Mass and Energy Balance}

The efficiency determination was based on mass and energy balances. They are fundamental for subsequent calculation of efficiency indicators. The balance residual is determined for ODM material balance and energy balance of the 33 investigated BPs (Equations (8) and (10)). Based on the balance residuals the credibility of measured mass and energy flows can be evaluated [4].

The results show negative as well as positive balance residuals for ODM material and energy balances, which may be caused by several reasons (Figure 2). Positive values indicate lower mass and energy output than input. Negative values indicate a higher mass and energy output than input. Random residuals cannot be completely avoided based on possible non-steady state conditions and the error in sampling regarding the place and time, e.g., the DM and ODM content of substrates show daily variation [31].

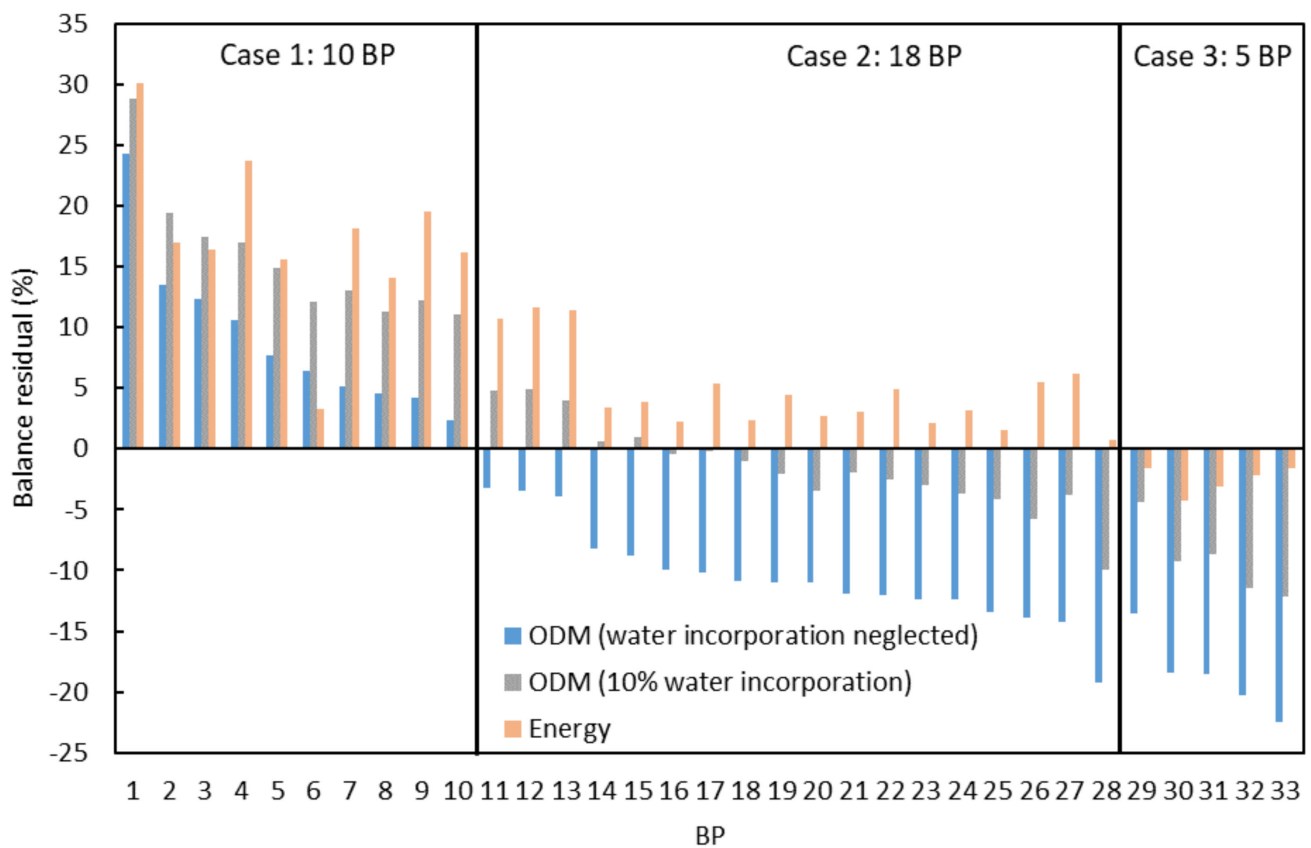

Figure 2. Balance residual of the organic dry matter content (ODM) material balance without and with considering a $10 \%$ water incorporation and the energy balance for 33 biogas plants (BP). A positive value means missing mass/energy in the output. BPs are grouped in three categories (Case 1: positive ODM and energy balance, Case 2: negative ODM balance and positive energy balance and Case 3: negative ODM and energy balance), sorted by the three cases at first and the ODM balance residual without consideration of water incorporation as second.

The accuracies of DM and ODM measurements between the laboratories have a small deviation of less than $1 \%$ and consequently only have a minor effect on the residuals, according to the internal validation of the participating laboratories. Therefore, the calculated residuals cannot solely be based on the measurement accuracy of the laboratory methods. Hence, a more likely reason is the on-site data accuracy.

Positive ODMBRs were observed for 10 BPs. A possible reason for a positive ODMBR is a too high assumed feeding mass by errors in measurement device as well as unknown 
and unrecorded substrate inputs. Addition of unrecorded substrate streams like rain water or silage seeping water lead to a dilution of digestate and therefore a lower ODM concentration, which consequently results in an underestimation of the digestate's potential. Another reason for positive ODMBRs could be the assumption of a too high CHP unit efficiency. This results in a lower calculated biogas yield and a positive ODMBR. A leakage of biogas from pipes and pressure relief valves leads to the same error.

In contrast, negative ODMBRs can result from an assumption of a too low CHP unit efficiency. An error in substrate mass measurement devices, e. g. by omitted calibration, can also lead to a negative ODMBR, if the measured mass is smaller than the real input mass.

However, both cases randomly occur across all plants and cannot explain that the most BPs (70\%) show negative ODMBRs. A methodical error is the neglect of water incorporation in ODM during the biogas production process. Water incorporation leads to an overestimation of ODM content via biogas output, as biogas is assumed to be built solely from ODM. Based on stoichiometric calculation for cellulose conversion the necessary water addition is $0.11 \mathrm{~g} \mathrm{~g}^{-1}$ Cellulose. This results in a fraction of $10 \%$ of biogas mass build from water. Pröter et al. [22] calculated a value of $11.25 \%$ of water incorporation in biogas for a maize silage. Using this factor of $11.25 \%$ water incorporation for the substrate mixtures of the BPs leads to an ODMBR of $-3 \%$ instead of $-7 \%$ averaged across all investigated biogas plants. However, for BPs with a positive ODMBR, the residuals increase proportionally (maximum $+29 \%$ instead of $+24 \%$ ). The extent of water incorporation depends on the substrate's constituents. The investigated BPs use diverse substrates in substrate mixtures, so that using a fixed value for respecting water incorporation for all BPs is not justifiable. Anyway, by disregarding water incorporation, negative ODMBRs are the expected case for accurate process data. Ultimately, the water incorporation only effects the ODM balance for checking the mass balances plausibility and not the mass balance itself.

Even though EBRs are also affected by measurement errors in mass balance, there are other possible factors responsible for the distribution. A positive EBR is observed at more than $80 \%$ of the BPs, which appears to be caused by two main factors. Energy outputs without a relation to the mass flow like heat and entropy loss based on exothermal reactions cannot be detected by the chosen approach. Furthermore, the calculated biogas yield might be too low due to overestimation of CHP unit's electrical efficiency or due to gas losses. Biogas loss can happen, amongst other reasons, through leakages and the pressure relief valves, just as Liebetrau et al. [32] determined emission factors of agricultural BPs to be in the range of 1.1 to $13.7 \% \mathrm{CH} 4$ of the total production. A third reason might be, like already mentioned for positive ODMBR, that unrecorded substrate mass was fed to the biogas plant. Even if this unrecorded mass was only water without energy content, it would lead to a wrong mass balance assuming to low digestate mass and therefore would cause a lower energy output by the digestate mass flow.

Negative EBRs are smaller than 5\% among all BPs and are only shown by $20 \%$ of the BPs. The negative EBRs are linked with the energy balance in which strongly negative ODMBRs also result in negative EBRs. Therefore, reasons for negative EBRs are the same as for negative ODMBRs, i.e., possibly underestimated input mass or underestimated CHP unit efficiency leading to overestimated biogas yields. A negative EBR can be reported only for BPs with a negative ODMBR of more than 14\%. This reveals the large impact of the mass balance, as errors here are reproduced in the energy balance.

The reflection of either ODMBR or EBRs alone does not allow a distinct decision regarding most probable errors and the credibility of the material and energy flows. The coherence of mass and energy balance reveals more useful information. From Figure 2, three cases can be distinguished:

(1) Positive ODM balance residual and positive energy balance residual

Ten BPs show a positive value of ODMBR and EBR. This positive ODMBR increases the positive EBR. For these few plants a clear positive error in feeding mass measurement device, an overestimation of CHP unit efficiency or biogas leakage is assumed. However, 
correction of this data is not possible in hindsight. Operators of these BPs should check the accuracy of their measurement devices and the efficiency of the CHP unit.

(2) Negative ODM balance residual and positive energy balance residual

Eighteen BPs show a negative ODMBR and positive EBR. This is attributed to water incorporation and entropy loss. A high data quality for the investigated BPs can be assumed, but more detailed research into water incorporation and entropy loss are necessary to be more specific. From the presented methodology this is the expected case.

(3) Negative ODM balance residual and negative energy balance residual

Five BPs show negative EBRs, which is generally impossible. However, the negative residuals are comparably small. In coherence with the negative ODMBRs the most probable errors are negative deviations in feeding mass measurement or an underestimated CHP unit efficiency. In this case, the accuracy of mass measurement should also be checked by plant operators.

The residuals follow reasonable directions only in case 2 . Therefore, the evaluation suggest that only the $55 \%$ of the examined biogas plants give credible results on mass and energy balances by the chosen approach.

BP 12 is a research biogas plant, where data quality is known to be accurate. This $\mathrm{BP}$ is one of the BPs with a negative ODM and a positive EBR. This fact strengthens the assumption that BPs with this combination are credible.

The findings can be further distinguished with regard to the diversity of the process parameters of the examined BPs. For BPs fed with $100 \%$ energy crops, in every case a negative ODMBR and a positive EBR has been found. The ODM balance of these BP are credible. Different to that all BP with a power production less than $100 \mathrm{~kW}$ and also 4 of $6 \mathrm{BP}$ with a manure content higher than $75 \%$ show a positive balance residual for energy and ODM. The reason for the latter is, that the installation of measurement devices, e.g., for manure mass flows, is not economically feasible on small-scale BPs. The balances of these plants are less credible.

The ODM and energy balance reveals the problems in carrying out an efficiency analysis. The analysis is based on both balances. The necessary assumptions and the use of on-site process data can result in low accuracy, mainly due to missing measurement equipment or inadequate calibration. The inability to determine water incorporation, entropy loss and gas loss for full-scale biogas plants prevent the determination of a correction factor.

\subsection{Specific Methane Potential}

The specific methane potentials (SMP) from substrate mixtures of 33 biogas plants (BP) in Figure 3 were determined by literature values of Association for Technology and Structures in Agriculture (KTBL), biochemical methane potential test (BMP), fermentable organic matter (FOM), energy of fermentable organic matter (EFOM), anaerobically degradable energy (adE), total energy (tE) and the on-site measured methane yield (on-site SMY). $\mathrm{SMP}_{\mathrm{KTBL}, \mathrm{SM}}, \mathrm{SMP}_{\mathrm{BMP}, \mathrm{SM}}, \mathrm{SMP}_{\mathrm{FOM}, \mathrm{SM}}$ and $\mathrm{SMP}_{\mathrm{EFOM}, \mathrm{SM}}$ show similar tendency for the specific methane potential between the BPs (Figure 3). The tendency is also similar to the on-site SMY, which is the specific methane yield of the fed substrate mixtures. This indicates a good sensitivity of the methods. However, $\mathrm{SMP}_{\mathrm{KTBL}, \mathrm{SM}}, \mathrm{SMP}_{\mathrm{BMP}, \mathrm{SM}}, \mathrm{SMP}_{\mathrm{FOM}, \mathrm{SM}}$ and $\mathrm{SMP}_{\mathrm{EFOM}, \mathrm{SM}}$ are mostly lower compared to the on-site SMY. The main reason is an underestimation of the potential by the methods, as discussed later. Another possible reason, like false process data, is only a possibility for 5 of 33 BPs (Case 3, Figure 3), by underestimation of the fed substrate mass and/or underestimation of CHP unit efficiency. 


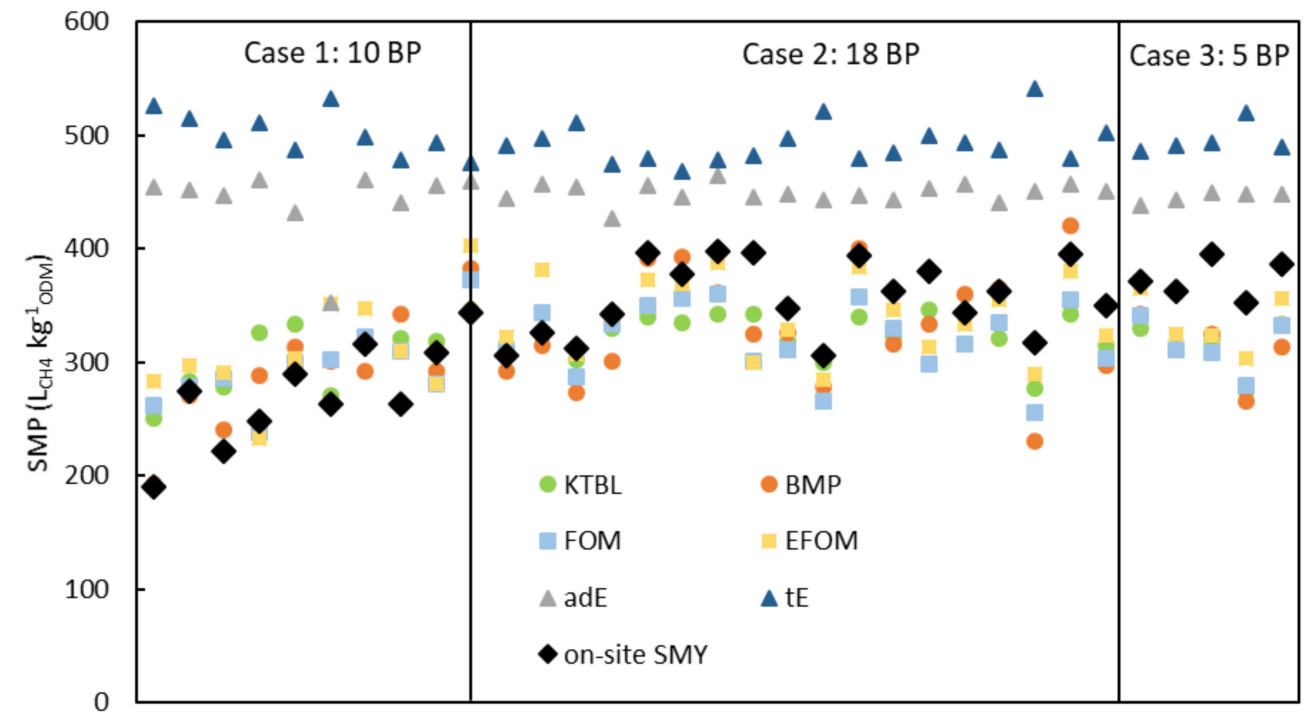

$123 \quad 4 \quad 5 \quad 6 \quad 7 \quad 899101112131415161718192021222324252627282930313233$

$\mathrm{BP}$

Figure 3. The specific methane potential (SMP) from substrate mixtures of 33 biogas plants (BP) determined by literature values of Association for Technology and Structures in Agriculture (KTBL), biochemical methane potential test (BMP), fermentable organic matter (FOM), energy of fermentable organic matter (EFOM), anaerobically degradable energy (adE), total energy ( $t E)$ and the on-site measured methane yield (on-site SMY). BPs are separated according to three cases (Case 1: positive ODM and energy balance, Case 2: negative ODM balance and positive energy balance and Case 3: negative ODM and energy balance).

$\mathrm{SMP}_{\mathrm{AdE}, \mathrm{SM}}$ and $\mathrm{SMP}_{\mathrm{tE}, \mathrm{SM}}$ are much higher than SMP of the other methods (Figure 3). As the methods for adE and $t E$ give energy values as results, they had to be converted to methane yields for comparison. This was done by dividing the energy values by the gross calorific value of methane (Equations (19) and (20)). By that, losses by chemical conversion of substrates to methane are neglected, leading to higher SMP values. Within the other methods, these losses are methodologically included.

$\mathrm{SMP}_{\mathrm{adE}, \mathrm{SM}}$ are lower than $\mathrm{SMP}_{\mathrm{tE}, \mathrm{SM}}$, as anaerobically non-degradable lignin in the substrates is subtracted from the total energy potential by using adE. The sensitivity of the calculated $\mathrm{SMP}_{\mathrm{tE}, \mathrm{SM}}$ and $\mathrm{SMP}_{\mathrm{adE}, \mathrm{SM}}$ is lower than for the other methods. This is expected for $\mathrm{SMP}_{\mathrm{tE}, \mathrm{SM}}$, as this value does not reflect the anaerobic degradability of the substrate mixture. In contrast, $\mathrm{SMP}_{\mathrm{adE}, \mathrm{SM}}$ respects the composition of the substrate mixture but does not respect the accessibility of the degradable components for microbial degradation. The degradable components hemicellulose and cellulose are typically incrusted by lignin, which makes them not accessible for microbial degradation without physical pretreatment.

Figures 2 and 3 indicate an effect between the SMY of a BP and the ODMBR. The SMY correlates also according to the fed manure (Table 1), because of less SMY of manure compared to energy crops.

Figure 3 also reveals the tendency that a negative ODM and energy balance follow in lower estimated SMP compared to the on-site SMY, during positive ODM and energy balance follow in a higher estimated SMP compared to the on-site SMY, according to an aforementioned probable negative/positive feeding mass error. These findings support the assumption, that the data quality is low for $45 \%$ of the BPs.

Besides the SMP of the substrate, the methane potentials of the digestate were used to determine the conversion efficiency (CE). Only the methods BMP, adE and tE determine the potential of digestate (Figure 4). For FOM and EFOM a required fermentation coefficient for the digestate is not determinable. 


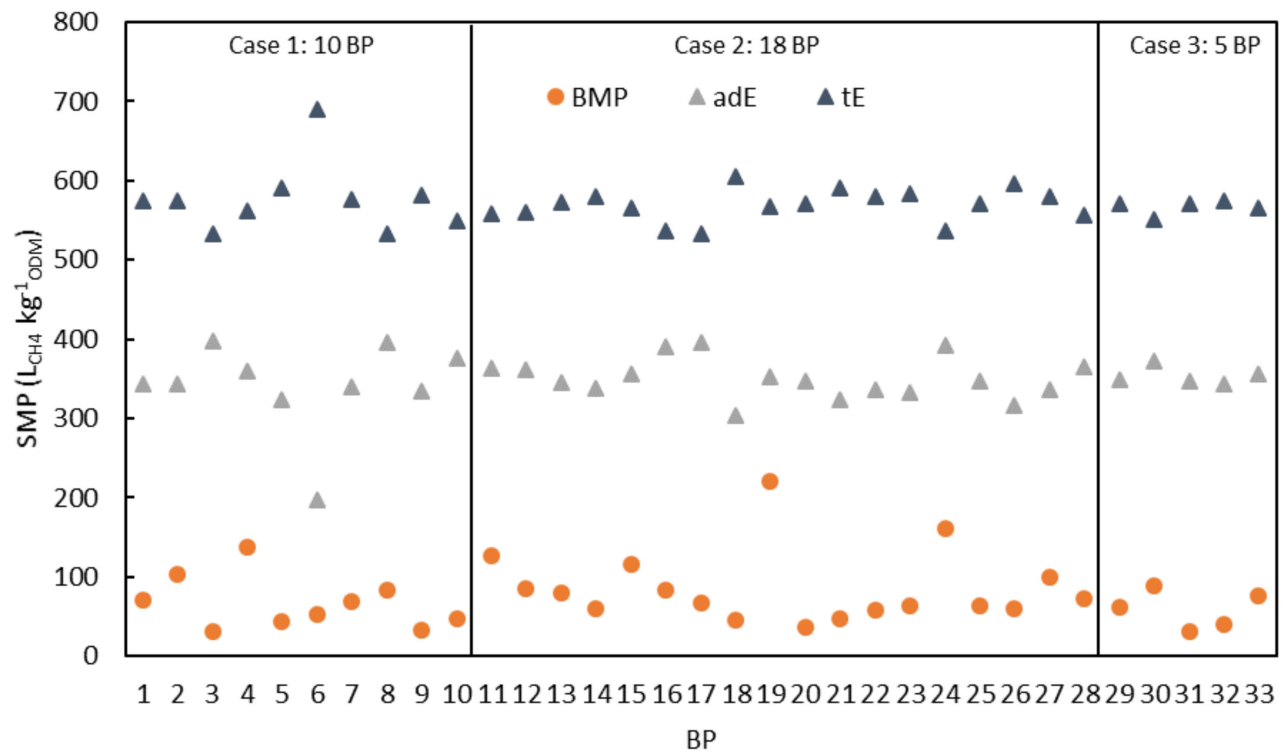

Figure 4. The spec. methane potential of digestate (SMP) of 33 biogas plants (BP) determined by biochemical methane potential test (BMP), anaerobically degradable energy (adE) and total energy (tE), based on the ODM in digestates.

In contrast to Figure 3 the SMP of digestates in Figure 4 were determined by biochemical methane potential test (BMP), anaerobically degradable energy (adE) and total energy $(\mathrm{tE})$, based on the ODM in digestates. Again, the energy of adE and $\mathrm{tE}$ was converted to SMP by dividing with the gross calorific value of methane and by that neglecting losses of conversion. The potentials show major differences based on different assumptions in the three methods.

$\mathrm{SMP}_{\mathrm{tE} \text {,dig }}$ was the highest calculated SMP and the values are even higher, than the SMP of the substrates calculated by this method, which is caused by using ODM-specific values. In accordance with the lignin ratio in ODM, the ODM specific energy in digestate is higher than in substrate. Since low calorific components of ODM are degraded (mainly carbohydrates with around 17-18 $\mathrm{MJ} \mathrm{kg}^{-1}$ ), high calorific lignin (around 25-26 $\mathrm{MJ} \mathrm{kg}^{-1}$ [23]) remains undigested. This is also the reason why the pattern of tE and adE of the $33 \mathrm{BPs}$ is symmetrical (Figure 4). Higher $\mathrm{SMP}_{\mathrm{tE}, \mathrm{dig}}$ means higher lignin contents, resulting in lower $\mathrm{SMP}_{\text {adE,dig. }}$.

The SMP $\mathrm{adE}_{\text {,dig }}$ in Figure 4 is around 3 times higher than $\mathrm{SMP}_{\mathrm{BMP}, \mathrm{dig}}$. Most probable reason for the difference is that hemicellulose and cellulose in the digestates are incrusted by lignin and not accessible for microbial degradation in BMP test. In median, based on the results of this study, $39 \%$ of the energy potential of the digestates are lignin. Additional $48 \%$ of the energy potential of the digestates are not accessible to microbial degradation, as calculated by the difference of adE and BMP. This should be the maximum possible potential, which is achievable with further treatment. Further research on this topic could lead to a useful parameter set in future. However it has to be mention, that the temperature effects the $\mathrm{SMP}_{\mathrm{BMP}, \mathrm{dig}}$ strongly [33].

\subsection{Conversion and Yield Efficiency}

The yield efficiencies (YE) were calculated for all BPs according to six different methods based on Equation (21). The results are listed in Table 2 grouped in the three described cases. The calculated YEs show a similar distribution like the SMPs calculated for different methods in Figure 3. Table 2 clearly shows that the mass balance also effects the results of YE for every method. BPs with a positive ODM and energy balance residual (case 1) show low YE for every method according to a positive feeding mass error. 
Table 2. Yield efficiency (YE) of 33 biogas plants (BP) determined by literature values of Association for Technology and Structures in Agriculture (KTBL), biochemical methane potential test (BMP), fermentable organic matter (FOM), energy fermentable organic matter (EFOM), anaerobically degradable energy ( $\mathrm{adE}$ ) and total energy ( $\mathrm{tE}$ ). The minimum (Min), maximum (Max) and median values were calculated for each parameter. The median of BP fitting Case 2 were also calculated. BP 12 is a research biogas plant with high measurement accuracy.

\begin{tabular}{|c|c|c|c|c|c|c|c|}
\hline & \multicolumn{7}{|c|}{ Yield Efficiency [\%] } \\
\hline & BP & BMP & KTBL & FOM & EFOM & adE & $\mathrm{tE}$ \\
\hline \multirow{10}{*}{ 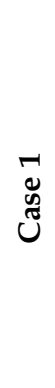 } & 1 & 98 & 76 & 73 & 67 & 42 & 36 \\
\hline & 2 & 101 & 97 & 98 & 92 & 61 & 53 \\
\hline & 3 & 92 & 79 & 77 & 76 & 50 & 45 \\
\hline & 4 & 86 & 76 & 104 & 107 & 54 & 49 \\
\hline & 5 & 92 & 87 & 96 & 95 & 67 & 59 \\
\hline & 6 & 88 & 98 & 87 & 75 & 75 & 50 \\
\hline & 7 & 108 & 99 & 98 & 91 & 69 & 63 \\
\hline & 8 & 77 & 82 & 85 & 85 & 60 & 55 \\
\hline & 9 & 106 & 97 & 110 & 110 & 68 & 62 \\
\hline & 10 & 90 & 99 & 92 & 85 & 75 & 72 \\
\hline \multirow{18}{*}{$\begin{array}{l}N \\
\tilde{y} \\
\tilde{u}\end{array}$} & 11 & 105 & 97 & 99 & 95 & 69 & 62 \\
\hline & 12 & 104 & 101 & 95 & 86 & 71 & 66 \\
\hline & 13 & 114 & 103 & 109 & 101 & 69 & 61 \\
\hline & 14 & 114 & 104 & 103 & 100 & 80 & 72 \\
\hline & 15 & 101 & 117 & 113 & 107 & 87 & 83 \\
\hline & 16 & 96 & 113 & 106 & 102 & 85 & 81 \\
\hline & 17 & 110 & 116 & 110 & 103 & 86 & 83 \\
\hline & 18 & 122 & 116 & 132 & 132 & 89 & 82 \\
\hline & 19 & 107 & 109 & 112 & 106 & 77 & 70 \\
\hline & 20 & 110 & 102 & 115 & 107 & 69 & 59 \\
\hline & 21 & 98 & 116 & 110 & 103 & 88 & 82 \\
\hline & 22 & 115 & 113 & 110 & 105 & 82 & 75 \\
\hline & 23 & 114 & 110 & 128 & 122 & 84 & 76 \\
\hline & 24 & 96 & 109 & 109 & 103 & 75 & 70 \\
\hline & 25 & 99 & 113 & 108 & 102 & 82 & 74 \\
\hline & 26 & 138 & 115 & 124 & 109 & 70 & 59 \\
\hline & 27 & 94 & 116 & 111 & 104 & 87 & 82 \\
\hline & 28 & 118 & 111 & 115 & 108 & 78 & 70 \\
\hline \multirow{9}{*}{$\begin{array}{l}n \\
\ddot{D} \\
\tilde{J}\end{array}$} & 29 & 109 & 113 & 109 & 102 & 85 & 76 \\
\hline & 30 & 100 & 116 & 116 & 111 & 82 & 74 \\
\hline & 31 & 122 & 124 & 128 & 122 & 88 & 80 \\
\hline & 32 & 132 & 129 & 126 & 116 & 79 & 68 \\
\hline & 33 & 123 & 116 & 116 & 109 & 86 & 79 \\
\hline & Min & 77 & 76 & 73 & 67 & 42 & 36 \\
\hline & Max & 138 & 129 & 132 & 132 & 89 & 83 \\
\hline & Median & 105 & 109 & 109 & 103 & 77 & 70 \\
\hline & Median Case 2 & 109 & 110 & 112 & 105 & 79 & 73 \\
\hline
\end{tabular}

Different from that, YE of BP with negative ODMBRs and EBRs (case 3) show a tendency for high $Y E$ according to a negative feeding mass error, but the difference to case 2 is not that obvious. Similar to YE in Table 2, CEs of all BPs are listed in Table 3. The CE was determined based on the potentials of the substrate and the digestate determined by BMP, FOM, EFOM, adE, tE and ODM (Table 3). Dependencies between process data, e.g., process temperature, HRT or OLR, and efficiency indicators were not observed and are therefore not presented. 
Table 3. Conversion efficiency (CE) of 33 biogas plants (BP) determined by biochemical methane potential test (BMP), fermentable organic matter (FOM), energy fermentable organic matter (EFOM), anaerobically degradable energy (adE), total energy ( $\mathrm{tE}$ ) and organic dry matter content (ODM). The minimum (Min), maximum (Max) and median value were calculated for each parameter. The median of BP fitting Case 2 were also calculated. BP 12 is a research biogas plant with high measurement accuracy.

\begin{tabular}{|c|c|c|c|c|c|c|c|}
\hline & \multicolumn{7}{|c|}{ Conversion Efficiency [\%] } \\
\hline & $\mathbf{B P}$ & BMP & FOM & EFOM & adE & $\mathrm{tE}$ & ODM \\
\hline \multirow{10}{*}{$\begin{array}{l}\vec{u} \\
\tilde{y} \\
\tilde{U}\end{array}$} & 1 & 89 & 101 & 123 & 77 & 66 & 69 \\
\hline & 2 & 90 & 104 & 121 & 80 & 70 & 73 \\
\hline & 3 & 95 & 80 & 104 & 68 & 61 & 64 \\
\hline & 4 & 96 & 133 & 159 & 80 & 72 & 75 \\
\hline & 5 & 97 & 123 & 120 & 84 & 75 & 79 \\
\hline & 6 & 94 & 86 & 80 & 80 & 53 & 64 \\
\hline & 7 & 96 & 91 & 117 & 88 & 82 & 84 \\
\hline & 8 & 93 & 99 & 107 & 75 & 69 & 72 \\
\hline & 9 & 98 & 121 & 144 & 89 & 82 & 85 \\
\hline & 10 & 99 & 100 & 104 & 92 & 88 & 90 \\
\hline \multirow{18}{*}{$\begin{array}{l}v \\
\tilde{y} \\
\tilde{y} \\
\tilde{u}\end{array}$} & 11 & 97 & 101 & 111 & 81 & 73 & 76 \\
\hline & 12 & 94 & 91 & 101 & 84 & 77 & 80 \\
\hline & 13 & 93 & 111 & 120 & 81 & 72 & 75 \\
\hline & 14 & 96 & 95 & 105 & 84 & 76 & 80 \\
\hline & 15 & 97 & 111 & 112 & 91 & 87 & 89 \\
\hline & 16 & 97 & 106 & 105 & 87 & 83 & 85 \\
\hline & 17 & 98 & 106 & 109 & 91 & 89 & 90 \\
\hline & 18 & 98 & 126 & 136 & 92 & 85 & 88 \\
\hline & 19 & 85 & 105 & 112 & 82 & 74 & 78 \\
\hline & 20 & 95 & 106 & 112 & 72 & 61 & 65 \\
\hline & 21 & 99 & 108 & 106 & 91 & 85 & 88 \\
\hline & 22 & 97 & 108 & 112 & 87 & 80 & 83 \\
\hline & 23 & 96 & 116 & 125 & 86 & 78 & 81 \\
\hline & 24 & 89 & 106 & 108 & 79 & 73 & 75 \\
\hline & 25 & 96 & 100 & 104 & 84 & 76 & 80 \\
\hline & 26 & 91 & 96 & 120 & 77 & 64 & 67 \\
\hline & 27 & 98 & 108 & 112 & 93 & 89 & 91 \\
\hline & 28 & 93 & 106 & 109 & 78 & 70 & 73 \\
\hline \multirow{9}{*}{ 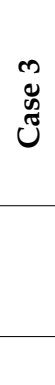 } & 29 & 97 & 104 & 100 & 83 & 75 & 79 \\
\hline & 30 & 93 & 97 & 105 & 77 & 69 & 73 \\
\hline & 31 & 98 & 115 & 117 & 85 & 77 & 80 \\
\hline & 32 & 95 & 104 & 112 & 76 & 66 & 69 \\
\hline & 33 & 95 & 101 & 106 & 84 & 77 & 80 \\
\hline & Min & 85 & 80 & 80 & 68 & 53 & 64 \\
\hline & Max & 99 & 133 & 159 & 93 & 89 & 91 \\
\hline & Median & 96 & 105 & 112 & 84 & 75 & 79 \\
\hline & Median Case 2 & 95 & 106 & 112 & 85 & 77 & 80 \\
\hline
\end{tabular}

The KTBL values and the BMP values are based on measured values in a BMP test. Both show a YE higher than $100 \%$. It appears that the methods underestimate the real SMP. The values of the research BP (BP 12) support these results even if the values are near to $100 \%$ (BMP 104\% and KTBL 101\%). Efficiency values higher than 100\% was also reported for both in literature [34,35]. Underestimation of SMP ${ }_{\mathrm{BMP}, \mathrm{SM}}$ and $\mathrm{SMP}_{\mathrm{KTBL}, \mathrm{SM}}$ can result, due to the effects of co-digestion in a full-scale BP instead of mono-digestion in the laboratory batch test [36,37]. Pöschel et al. [38] estimated $10 \%$ higher values. Other possible reasons could be methodological differences between lab and full-scale, like the higher temperature in a full-scale biogas plant, a higher consumption for bacterial growth based 
on a missing steady state condition in laboratory tests as well as unacclimated inoculum or a too short HRT in laboratory tests [39].

$\mathrm{CE}_{\mathrm{BMP}}$ is the state-of-the-art method to determine the CE. A CE higher than $100 \%$ is not possible for this method. The CE reveals the achievable extra potential by extending the HRT of gas-tight digesters for 60 days in a $37^{\circ} \mathrm{C}$ heated digester. In Germany, the total HRT of gas-tight digesters built after 2016 and the HRT of a secondary digester built after 2011 are already higher than 150 days according to EEG 2017. This leads to a high $\mathrm{CE}_{\mathrm{BMP}}$ found in this study and also to a small spread in the values, which corresponds to results by Ruile et al. of 21 German biogas plants [5]. The $\mathrm{CE}_{\mathrm{BMP}}$ reveals a small potential in increasing the digestion duration nowadays compared to lower $\mathrm{CE}_{\mathrm{BMP}}$ in other former studies $[5,33,40]$, which is supported by a comparison of the $\mathrm{SMP}_{\mathrm{BMP}}$ to the $\mathrm{SMP}_{\mathrm{BMP}}$ of former studies [34,41]. Further optimization cannot be done for most BPs based on this. However, it is the only CE method, which can show the reachable potential by a longer HRT. This information is of interest for BPs operation in different countries today. For three outliers with a $\mathrm{CE}_{\mathrm{BMP}}$ lower than $90 \%$, clear reasons can be found, e.g., low retention time in heated system by feeding substrate with a high lignin content.

$\mathrm{CE}_{\mathrm{FOM}}$ and $\mathrm{CE}_{\mathrm{EFOM}}$ show a higher spread for $\mathrm{CE}$, but $\mathrm{CE}$ and $\mathrm{YE}$ higher than $100 \%$ can be reported for both. Values higher than $100 \%$ for $\mathrm{YE}_{\mathrm{EFOM}}$ and $\mathrm{YE}_{\mathrm{FOM}}$ are reasoned by underestimated SMP of the substrate. Lower residual ODM masses in the digestates than are expected by the fermentation coefficients used in these methods are responsible for $\mathrm{CE}_{\mathrm{EFOM}}$ and $\mathrm{CE}_{\mathrm{FOM}}$ values above $100 \%$. Based on the results, the applied substrate specific fermentation coefficients are too low. In order to utilize FOM and EFOM for CE or YE calculations, more research on fermentation coefficients is necessary. Especially, the variability of manure cannot be considered adequately by using a fixed fermentation coefficient, which only depends on the type of manure. For the research BP, both methods show a value lower than 100\% (FOM 95\% and EFOM 86\%). Weißbach [42] analyzed the efficiency of three different biogas fermenters of the same biogas plant based on FOM and found CEs between 96.4 and $99.5 \%$ and YEs between 99.7 and $103.7 \%$.

$\mathrm{YE}_{\mathrm{adE}}$ and $\mathrm{YE}_{\mathrm{tE}}$ are throughout lower than 100\%, which is lower than found with other methods. For the research plant BP 12 adE reach a value of $71 \%$ and $\mathrm{tE}$ of $66 \%$. As $\mathrm{YE}_{\mathrm{adE}}$ is applied for the first time here, comparative literature values are missing. However, it is possible to calculate expected values by stoichiometry with the so called Buswell's formula [43]. For example, for cellulose a maximum $\mathrm{YE}_{\mathrm{adE}}$ of $95 \%$ can be expected based on a GCV of cellulose of $17.3 \mathrm{MJ} \mathrm{kg}^{-1}$. Based on the reference value for the specific methane yield of cellulose from VDI 4630 [9], a $\mathrm{YE}_{\mathrm{adE}}$ of $86 \%$ is expected. For cellulose, $\mathrm{YE}_{\mathrm{adE}}$ and $\mathrm{YE}_{\mathrm{tE}}$ are equal, as cellulose is completely degradable under anaerobic conditions. The example shows, that the calculated $\mathrm{YE}_{\mathrm{adE}}$ of the examined BPs are in a reasonable range.

$\mathrm{CE}_{\mathrm{adE}}$ and $\mathrm{CE}_{\mathrm{tE}}$ are lower than $\mathrm{CE}$ with other methods and show a higher spread compared to $\mathrm{CE}_{\mathrm{BMP}}$. The $\mathrm{CE}_{\mathrm{adE}}$ is lower than $\mathrm{CE}_{\mathrm{BMP}}$ in every case as expected by the different residual SMP in the digestates. Comparison of $\mathrm{CE}_{\mathrm{adE}}$ and $\mathrm{CE}_{\mathrm{tE}}$ shows the energy potential in lignin. The study reveals that in median $9 \%$ of the total energy of the substrate is stored in lignin. $\mathrm{CE}_{\mathrm{tE}}$ and $\mathrm{YE}_{\mathrm{tE}}$ can be used as a reference to compare the biogas process with other biomass conversion processes, like ethanol production, pyrolysis or biomass combustion. Moreover, $\mathrm{CE}_{\mathrm{tE}}$ is revealing how much additional energy can be utilized from the digestate. $11-7 \%$ of the total energy potential is not used by the BPs according to the results of this work. Bio-economy concepts could increase the utilization of the potential. However, $\mathrm{CE}_{\mathrm{tE}}$ and $\mathrm{YE}_{\mathrm{tE}}$ are also strongly affected by the used substrate similar to $\mathrm{CE}_{\mathrm{ODM}}$ and thereby hinder the comparison of BPs, which use substrates with different degradability.

$\mathrm{CE}_{\mathrm{ODM}}$ is used several times for determining the $\mathrm{CE}$ and a clear divergence between the BPs can be reported. It is clearly impacted by the fed substrate. The ODM of maize is nearly completely anaerobically degradable, because of the low lignin content. Compared to that, cattle manure has a higher lignin content and a lower $\mathrm{CE}_{\mathrm{ODM}}$. Therefore a comparison of two BPs with different feedstock like done here would not be useful []. $\mathrm{CE}_{\mathrm{tE}}$ 
and $\mathrm{CE}_{\mathrm{ODM}}$ are strongly dependent to each other. Only for one BP the two parameters show $11 \%$ difference to each other. In every other case $\mathrm{CE}_{\mathrm{ODM}}$ is $1-4 \%$ higher than $\mathrm{CE}_{\mathrm{tE}}$ as expected, due to the linkage of ODM content and gross calorific value.

As shown, CE or YE are strongly dependent on the SMP of the substrate. KTBL, BMP, FOM and EFOM underestimate the substrate potential. AdE and $\mathrm{tE}$ are more coherent, but the sensitivity to the on-site methane yields of the BPs is low and the substrate's degradability, as an interaction between biomass composition and accessibility for degradation, is not fully considered. Hence, more research is necessary to investigate and implement influencing factors on SMP, especially to describe the differences between laboratory scale, where most of the determination methods were developed and commercial full-scale digestion, where the methods are to be applied. Typically, the accuracy of measurements is higher in laboratory experiments, but process conditions differ to those in full-scale biogas plants. From this point of view, it was a necessity to compare the methods with data from full-scale biogas plants, even though high measurement accuracy is difficult to achieve, as shown with presented mass and energy balances.

\section{Conclusions}

Overall, the results of the current research show that benchmarking agricultural biogas plants is challenging regardless of the method chosen. It is worthwhile to check the reliability of the recorded operating parameters by evaluating mass and energy balances, as shown by the fact that plausible results were obtained for only $55 \%$ of the investigated biogas plants. Regular calibration of the measuring instruments is therefore highly recommended for determining the biological efficiency but is repeatedly neglected under practical conditions. However, this had no influence on the comparison of the different methods, as the statements were similar for all BPs.

A conclusive recommendation for a specific method to evaluate efficiency is not possible. $Y E_{K T B L}, \mathrm{YE}_{\mathrm{BMP}}, \mathrm{YE}_{\mathrm{FOM}}$ and $\mathrm{Y} \mathrm{E}_{\mathrm{EFOM}}$ show a good relation to the field measurements, but all underestimate the methane potentials of the substrate. The probable reason for this is an underestimation of the fermentable fraction of the substrate. These conclusions are supported by the fact that $\mathrm{CE}_{\mathrm{FOM}}$ and $\mathrm{CE}_{\mathrm{EFOM}}$ being higher than $100 \%$. To avoid this, further research is necessary, e.g., towards substrate characterization. The results of $\mathrm{YE}_{\mathrm{adE}}$ and $\mathrm{YE}_{\mathrm{tE}}$, as well as $\mathrm{CE}_{\mathrm{adE}}$ and $\mathrm{CE}_{\mathrm{tE}}$, are more coherent, but the sensitivity is low and the degradability of the substrate as an interaction between biomass composition and degradability is not fully considered. Based on the YE data, an evaluation of the BPs is not possible and not done here. A combination of $\mathrm{CE}_{\mathrm{BMP}}$ and $\mathrm{CE}_{\mathrm{adE}}$ is a promising approach, as it can reveal the achievable potential of further substrate pretreatments. This combination should be investigated in further research. Besides the values of $\mathrm{CE}_{\mathrm{BMP}}$, an evaluation of biogas plant operation is difficult as reference values are missing.

Supplementary Materials: The following are available online at https: / www.mdpi.com/article / 10.3390/en14092381/s1, Table S1: Substrates ratio of feeding of the 33 investigated biogas plants $(\mathrm{BP}), \mathrm{MS}=$ maize silage, $\mathrm{GS}=$ gras silage, $\mathrm{WPS}=$ whole plant silage, $\mathrm{SB}=$ sugar beet, $\mathrm{CE}=$ cereals, $\mathrm{PO}=$ Potato, $\mathrm{LCM}=$ liquid cow manure, $\mathrm{SCM}=$ solid cow manure, $\mathrm{HM}=$ horse manure, $\mathrm{CM}=$ chicken manure, $\mathrm{LPM}=$ liquid pig manure, $\mathrm{SM}=$ sheep manure, $\mathrm{ML}=$ molasses of lactose production, $\mathrm{BT}=$ brewer's spent grains, $\mathrm{FO}=$ Fodder residuals, $\mathrm{OT}=$ others.

Author Contributions: Conceptualization, B.H., T.M. and M.P.; methodology, B.H., T.M. and M.P.; software, B.H. and T.M.; validation, B.H., T.M. and M.P.; formal analysis, B.H., T.M. and M.P.; investigation, B.H., T.M. and M.P.; resources, B.H., T.M., M.P., H.O., J.L., E.H. and J.M.; data curation, B.H., T.M. and M.P.; writing—original draft preparation, B.H., T.M. and M.P.; writing—review and editing, H.O., J.L., E.H. and J.M.; visualization, B.H., T.M. and M.P.; supervision, H.O., J.L., E.H. and J.M.; project administration, H.O., J.L., E.H. and J.M.; funding acquisition, H.O., J.L., E.H. and J.M. All authors have read and agreed to the published version of the manuscript. 
Funding: This research was funded by Fachagentur Nachwachsende Rohstoffe (FNR), Gülzow, Germany; and the Federal Ministry of Food and Agriculture (BMEL), Berlin, Germany Germany [grant number 22403715]; This work was done in the project biogas measurement program III.

Institutional Review Board Statement: Not Applicable.

Informed Consent Statement: Not Applicable.

Data Availability Statement: Not Applicable.

Acknowledgments: Thanks goes to the project partners Bavarian State Research institute for Agriculture (LfL) and to person Robert Kliche and Matthias Effenberger. Furthermore: we would like to thank Jan Postel, Erik Fischer and Markus Lenhart for their contributions.

Conflicts of Interest: The authors declare no conflict of interest. The funders had no role in the design of the study; in the collection, analyses, or interpretation of data; in the writing of the manuscript, or in the decision to publish the results.

\section{References}

1. FNR. Entwickelung der Biogasanlagenstandorte in Deutschland. Available online: https://mediathek.fnr.de/grafiken/datenund-fakten/bioenergie/biogas/entwicklung-der-biogasanlagenstandorte-in-deutschland.html (accessed on 14 April 2021).

2. Torrijos, M. State of Development of Biogas Production in Europe. Procedia Environ. Sci. 2016, 35, 881-889. [CrossRef]

3. Daniel-Gromke, J.; Rensberg, N.; Denysenko, V.; Stinner, W.; Schmalfuß, T.; Scheftelowitz, M.; Nelles, M.; Liebetrau, J. Current Developments in Production and Utilization of Biogas and Biomethane in Germany. Chem. Ing. Tech. 2008, 90, 17-35. [CrossRef]

4. Schievano, A.; D'Imporzano, G.; Salati, S.; Adani, F. On-field study of anaerobic digestion full-scale plants (Part I): An on-field methodology to determine mass, carbon and nutrients balance. Bioresour. Technol. 2011, 102, 7737-7744. [CrossRef] [PubMed]

5. Ruile, S.; Schmitz, S.; Mönch-Tegeder, M.; Oechsner, H. Degradation efficiency of agricultural biogas plants-A full-scale study. Bioresour. Technol. 2015, 178, 341-349. [CrossRef] [PubMed]

6. Hartmann, H.; Ahring, B.K. Anaerobic digestion of the organic fraction of municipal solid waste: Influence of co-digestion with manure. Water Res. 2005, 39, 1543-1552. [CrossRef]

7. Demirer, G.N.; Chen, S. Effect of retention time and organic loading rate on anaerobic acidification and biogasification of dairy manure. J. Chem. Technol. Biotechnol. 2014, 79, 1381-1387. [CrossRef]

8. Schievano, A.; D’Imporzano, G.; Orzi, V.; Adani, F. On-field study of anaerobic digestion full-scale plants (Part II): New approaches in monitoring and evaluating process efficiency. Bioresour. Technol. 2011, 102, 8814-8819. [CrossRef]

9. VDI 4630. Fermentation of organic materials-Characterisation of the Substrate, Sampling, Collection of Material Data, Fermentation Tests; Verlag des Vereins Deutscher Ingenieure: Düsseldorf, Germany, 2016.

10. Weinrich, S.; Schäfer, F.; Bochmann, G.; Liebetrau, J. Value of batch tests for biogas potential analysis. Method comparison and challenges of substrate and efficiency evaluation of biogas plants. IEA Bioenergy Task 2018, 37, 13-28.

11. Hülsemann, B.; Zhou, L.; Merkle, W.; Hassa, J.; Müller, J.; Oechsner, H. Biomethane Potential Test: Influence of Inoculum and the Digestion System. Appl. Sci. 2020, 10, 2589. [CrossRef]

12. KTBL. Faustzahlen Biogas, 3rd ed.; KTBL: Darmstadt, Germany, 2013.

13. Weißbach, F. On Assessing the Gas Production Potential of Renewable Primary Products. Landtechnik 2008, 63, 356-358. [CrossRef]

14. Weißbach, F. Gas production potential of fresh and ensiled sugar beets in biogas production. Landtechnik 2009, 64, 394-397. [CrossRef]

15. Weißbach, F. The gas forming potential of pig slurry in biogas production. Landtechnik 2011, 66, 460-464. [CrossRef]

16. Weißbach, F. The gas forming potential of dry chicken dung in biogas production. Landtechnik 2012, 67, 299-304. [CrossRef]

17. Weißbach, F. Gas production potential of forage and cereal crops in biogas production. Landtechnik 2009, 64, 317-321. [CrossRef]

18. Mächtig, T.; Moschner, C.R.; Hartung, E. Monitoring the efficiency of biogas plants-Correlation between gross calorific value and anaerobically non-degradable organic matter of digestates. Biomass Bioenergy 2019, 130, 105389. [CrossRef]

19. Fischer, E.; Postel, J.; Ehrendreich, F.; Nelles, M. Using the mean fuel efficiency to energetically assess agricultural biogas plants. Agric. Eng. 2016, 71, 139-154. [CrossRef]

20. Biogas-Messprogramm III, 1st ed.; Fachagentur Nachwachsende Rohstoffe: Gülzow, Germany, 2021.

21. DIN EN 15935:2012-11, Sludge, Treated Biowaste, Soil and Waste_Determination of Loss on Ignition; Beuth Verlag GmbH: Berlin, Germany, 2012.

22. Pröter, J.; Weinrich, S.; Hofman, J.; Kube, J. Mass balancing of biogas plants. In Collection of Methods for Biogas, 2nd ed.; Liebetrau, J., Pfeiffer, D., Eds.; DBFZ: Leipzig, Germany, 2020; pp. 381-392.

23. Apelt, M. Determination of aliphatic, organic acids and benzaldehyde with headspace GC. In Collection of Methods for Biogas, 2nd ed.; Liebetrau, J., Pfeiffer, D., Eds.; DBFZ: Leipzig, Germany, 2020; pp. 64-68.

24. Steinbrenner, J.; Nägele, H.-J.; Buschmann, A.; Hülsemann, B.; Oechsner, H. Testing different ensiling parameters to increase butyric acid concentration for maize silage, followed by silage separation and methane yield potential of separated solids residues. Bioresour. Technol. Rep. 2019, 7, 100193. [CrossRef] 
25. VDLUFA. Federation of German Agricultural Investigation and Research Institutes; VDLUFA Verlag: Darmstadt, Germany, 2007.

26. Dittrich-Zechendorf, M. Determination of total Kjeldahl nitrogen and crude protein. In Collection of Methods for Biogas, 2nd ed.; Liebetrau, J., Pfeiffer, D., Eds.; DBFZ: Leipzig, Germany, 2020; pp. 90-100.

27. DIN EN ISO 18125:2017-08, Solid Biofuels-Determination of Calorific Value; Beuth Verlag GmbH: Berlin, Germany, 2017.

28. Havukainen, J.; Uusitalo, V.; Niskanen, A.; Kapustina, V.; Horttanainen, M. Evaluation of methods for estimating energy performance of biogas production. Renew. Energy 2014, 66, 232-240. [CrossRef]

29. Aschmann, V.; Effenberger, M. The electrical efficiency of biogas-driven combined heat and power plants. Agric. Eng. 2012, 67, 118-121. [CrossRef]

30. DIN EN ISO 6976:2016-12, Natural Gas-Calculation of Calorific Values, Density, Relative Density and Wobbe Indices from Composition; Beuth Verlag GmbH: Berlin, Germany, 2016.

31. Banks, C.J.; Chesshire, M.; Heaven, S.; Arnold, R. Anaerobic digestion source-segregated domestic food waste: Performance assessment by mass and energy balance. Bioresour. Technol. 2011, 102, 612-620. [CrossRef] [PubMed]

32. Liebetrau, J.; Reinelt, T.; Clemens, J.; Hafermann, C.; Friehe, J.; Weiland, P. Analysis of greenhouse gas emissions from 10 biogas plants within the agricultural sector. Water Sci. Technol. 2013, 67, 1370-1379. [CrossRef] [PubMed]

33. Angelidaki, I.; Boe, K.; Ellegaard, L. Effect of operating conditions and reactor configuration on efficiency of full-scale biogas plants. Water Sci. Technol. 2005, 52, 189-194. [CrossRef]

34. Lansing, S.; Hülsemann, B.; Choudhury, A.; Schueler, J.; Lisboa, M.S.; Oechsner, H. Food waste co-digestion in Germany and the United States: From lab to full-scale systems. Resour. Conserv. Recycl. 2019, 148, 104-113. [CrossRef]

35. KTBL. Gasausbeute in Landwirtschaftlichen Biogasanlagen. KTBL-Heft 107, 3rd ed.; KTBL: Darmstadt, Germany, $2015 ;$ p. 27.

36. Mata-Alvarez, J.; Macé, S.; Llabrés, P. Anaerobic digestion of organic solid wastes. An overview of research achievements and perspectives. Bioresour. Technol. 2000, 74, 3-16. [CrossRef]

37. Astals, S.; Batstone, D.J.; Mata-Alvarez, J.; Jensen, P.D. Identification of synergistic impacts during anaerobic co-digestion of organic wastes. Bioresour. Technol. 2014, 169, 421-427. [CrossRef]

38. Pöschel, M.; Ward, S.; Owende, P. Evaluation of energy efficiency of various biogas production and utilization pathways. Appl. Energy 2010, 87, 3305-3321. [CrossRef]

39. Browne, J.D.; Murphy, J.D. Assessment of the resource associated with biomethane from food waste. Appl. Energy 2013, 104, 170-177. [CrossRef]

40. Weiland, P.; Gemmeke, B.; Rieger, C. Biogas-Messprogramm II: 61 Biogasanlagen im Vergleich; Gülzow-Prüzen, Germany, 2009, ISBN 978-3-9803927-8-5. Available online: https:/ / www.fnr-server.de/ftp/pdf/literatur/pdf_385-messprogramm_ii.html (accessed on 20 April 2021).

41. Zhou, L.; Hülsemann, B.; Cui, Z.; Merkle, W.; Sponagel, C.; Zhou, Y.; Guo, J.; Dong, R.; Müller, J.; Oechsner, H. Operating Perfomance of Full-Scale Agricultural Biogas Plants in Germany and China: Results of a Year-Round Monitoring Program. Appl. Sci. 2021, 11, 1271. [CrossRef]

42. Weißbach, F. Degree of utilization of primary renewable products in biogas production. Landtechnik 2009, 64, 18-21. [CrossRef]

43. Symons, G.E.; Buswell, A.M. The Methane Fermentation of Carbohydrates. J. Am. Chem. Soc. 1933, 55, 2028-2036. [CrossRef] 